\title{
Elastic anisotropy of Tambo gneiss from Promontogno, Switzerland: a comparison of crystal orientation and microstructure-based modelling and experimental measurements
}

\author{
R.N. Vasin,,${ }^{1,2}$ H. Kern, ${ }^{3}$ T. Lokajíček, ${ }^{4}$ T. Svitek, ${ }^{4}$ E. Lehmann, ${ }^{5}$ D.C. Mannes, ${ }^{5}$ \\ M. Chaouche ${ }^{6}$ and H.-R. Wenk ${ }^{1}$ \\ ${ }^{1}$ Department of Earth and Planetary Science, University of California, Berkeley, CA, USA. E-mail: wenk@berkeley.edu \\ ${ }^{2}$ Joint Institute for Nuclear Research, Dubna, Moscow Region, Russia \\ ${ }^{3}$ Institut für Geowissenschaften, Universität Kiel, Kiel, Germany \\ ${ }^{4}$ Institute of Geology of the CAS, v.v.i., Prague, Czech Republic \\ ${ }^{5}$ Paul Scherrer Institute, Villigen, Switzerland \\ ${ }^{6}$ Laboratoire de Mécanique et Technologie, ENS-Cachan/CNRS/Paris-Saclay University, France
}

Accepted 2017 January 3. Received 2016 October 30; in original form 2016 June 13

\begin{abstract}
SUMMAR Y
Felsic and mafic gneisses constitute large proportions of the upper and lower continental crust. Gneisses often display high anisotropy of elastic properties associated with preferred orientations of sheet silicates. Here we study the elastic anisotropy of a sample of Tambo gneiss from Promontogno in the Central Alps. We apply optical microscopy, time-of-flight neutron diffraction, neutron and X-ray tomography to quantify mineral composition and microstructures and use them to construct self-consistent models of elastic properties. They are compared to results of ultrasonic measurements on a cube sample in a multi-anvil apparatus and on a spherical sample in an apparatus that can measure velocities in multiple directions. Both methods provide similar results. It is shown that models of microstructure-derived elastic properties provide a good match with ultrasonic experiment results at pressures above $100 \mathrm{MPa}$. At a pressure of $0.1 \mathrm{MPa}$ the correspondence between the model and the experiment is worse. This may be caused by an oversimplification of the model with respect to microfractures or uncertainties in the experimental determination of $S$-wave velocities and elastic tensor inversion. The study provides a basis to determine anisotropic elastic properties of rocks either by ultrasonic experiments or quantitative models based on microstructures. This information can then be used for interpretation of seismic data of the crust.
\end{abstract}

Key words: Numerical solutions; Microstructures; Elasticity and anelasticity; Seismic anisotropy; Acoustic properties.

\section{INTRODUCTION}

It has become well established that large sectors of the crust and upper mantle are composed of rocks which are anisotropic for seismic waves. This holds, in particular for the laminated lower continental crust (e.g. Meissner et al. 2006) as well as for ductile shear zones (e.g. Christensen \& Szymanski 1988; Kern \& Wenk 1990; Barruol et al. 1992). Therefore, the role of seismic anisotropy in understanding the evolution of the Earth's crust is becoming increasingly important, because the seismic anisotropy has a structural origin. Coupling experimental measurements of $P$ - and $S$-wave velocities with respective calculated $P$ and $S$ waves based on microstructural information may provide important clues for the understanding of the nature of seismic anisotropy revealed by seismic surveys. Major constituents of the upper and lower continental crust are felsic and mafic gneisses with anisotropy mainly defined by the alignment of phyllosilicates and amphiboles, respectively.

Increasingly new methods are used to characterize anisotropic properties of sheet silicate-containing rocks. Microstructures are investigated with light and electron microscopy, the 3-D grain arrangement is explored with computed neutron and X-ray tomography and crystal preferred orientations (CPO) are quantified based on neutron, X-ray and electron diffraction measurements. Acoustic velocity measurements have traditionally been performed on cubes (e.g. Kern et al. 1997, 2009) and cylinders (e.g. Christensen 1974; Ji \& Salisbury 1993; Cholach et al. 2005). A method to measure $P$ wave velocities on spheres up to a hydrostatic pressure of $400 \mathrm{MPa}$ was developed more than 40 yr ago by Pros \& Babuška (1968). This method was recently refined to allow simultaneous measurement of $P$ and $S$ waves in arbitrary directions at hydrostatic pressures up to 
$100 \mathrm{MPa}$ (Lokajíček et al. 2014). Here we follow up on previous work where elastic wave velocities have been measured on spheres and cubes (e.g. Lokajíček et al. 2014; Kern et al. 2015), with the possibility to derive complete elastic properties of the rock, estimate pore distribution and compare these data with models based on microstructural information. Much emphasis has been on studying anisotropy in shales (e.g. Hornby et al. 1994; Sayers 1994, Vasin et al. 2013) because of the large interest in the structure and properties of hydrocarbon reservoirs. In this contribution, we apply similar methods to a sample of a very homogeneous gneiss from the Central Alps. A main focus of the investigation is to calculate the elastic properties of the multiphase gneiss based on CPO data obtained by neutron diffraction texture measurements and to compare them with data derived from experimental velocity measurements on cubes and spheres. In addition, neutron and X-ray tomography is used to provide additional information about 3-D microstructures.

\section{LOCAL GEOLOGY AND SAMPLES}

Tambo gneiss composes the basis of the Tambo nappe, one of the higher Pennine nappes in the Central Alps, that extends from Pizzo Tambo in the NW to Vicosoprano in Val Bregaglia in the SE. Tambo gneiss was originally a Hercynian granite $(\mathrm{Rb} / \mathrm{Sr}$ age $\sim 293 \mathrm{Myr}$, Gulson 1973; Baudin et al. 1993) that was metamorphosed during the Alpine orogeny (ages are 35.5 Myr for muscovite and 24.0 Myr for biotite, Jäger 1973). Originally mostly megacrystic granite transformed into augengneiss and gneiss. A homogeneous variety is mined in two quarries, in Soglio and Promontogno in Val Bregaglia. A particular property is that the rock easily cleaves into perfectly planar sheets that extend over metres and are used for large stone tables, roof plates and floors (Fig. 1a). In Promontogno Tambo gneiss is in lower amphibolite metamorphic facies, with biotite and hornblende in adjacent rocks.

A block of Tambo gneiss used in this study was collected in the Promontogno quarry. The block was then cut into segments with

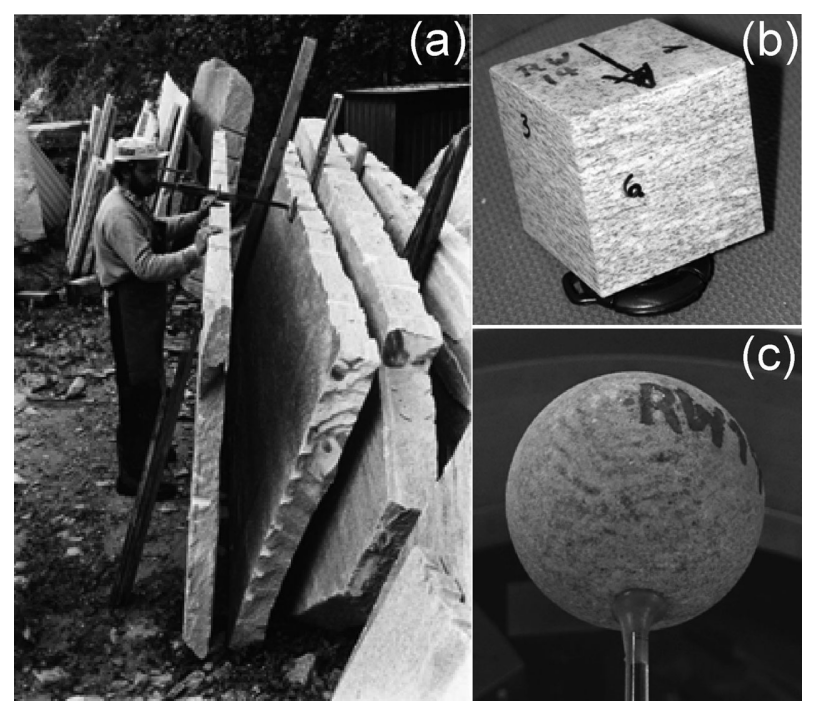

Figure 1. (a) Tambo gneiss sheets in Promontogno quarry. (b) Tambo gneiss cube (43 mm on edges) used for the velocity measurements in the multi-anvil apparatus in Kiel. Face 1 of the cube is parallel to the foliation; arrow marks the lineation direction. (c) Spherical $50 \mathrm{~mm}$ diameter Tambo gneiss sample used for velocity measurements in Prague and for CPO measurements with the SKAT diffractometer in Dubna; the dot at the top marks the foliation normal. a diamond saw. A cube with edge length of $43 \mathrm{~mm}$ (Fig. 1b) and a spherical sample of $50 \mathrm{~mm}$ diameter (Fig. 1c) were prepared for velocity measurements of $P$ - and $S$-wave velocities at hydrostatic pressures up to $400 \mathrm{MPa}$ for $P$ waves and $400 \mathrm{MPa}$ for $S$ waves on the cube and $100 \mathrm{MPa}$ on the sphere. Spheres are prepared by means of core drilling in the three perpendicular directions. Core diameter is $52 \mathrm{~mm}$. The obtained rock piece is then semiautomatically ground by two convex diamond half-spheres. Such an approach allows producing spherical samples with a diameter of $50 \pm 0.01 \mathrm{~mm}$. After the grinding the sphere is vacuum dried at $40{ }^{\circ} \mathrm{C}$ for $3 \mathrm{~d}$ and covered by the thin layer of epoxy resin to protect the specimen pore space against the hydrostatic medium oil. The same sphere was used for neutron diffraction and neutron tomography experiments. From the same block petrographic thin sections have been prepared for the optical analysis of the material and a rectangular sample with $\approx 2 \mathrm{~cm}$ edges for X-ray tomography studies. For all these investigations the same orthogonal coordinate system $\{X, Y, Z\}$ was used with $Z$ perpendicular to the welldefined schistosity plane and $X$ parallel to the more poorly defined lineation.

Overall, the sample is a homogeneous muscovite gneiss. The Tambo gneiss is mainly composed of four rock-forming minerals: quartz, albite, orthoclase and muscovite. Biotite, chlorite and pyrite are also present in minor quantities.

\section{EXPERIMENTAL TECHNIQUES AND INSTRUMENTS}

A microscopic inspection of thin sections was performed with the Zeiss petrographic microscope Axiophot.

The chemical composition of the Tambo gneiss was studied on a powder sample, using an ARL 9400 X-ray fluorescence analyser, working at $60 \mathrm{kV}$ (Institute of Chemical Technology, Prague).

Texture measurements of the sample have been performed with the SKAT time-of-flight neutron diffractometer (Ullemeyer et al. 1998; Keppler et al. 2014) installed at beamline 7A2 of the IBR-2 pulsed reactor (FLNP JINR, Dubna, Russia). The standard setup of the diffractometer including $19{ }^{3} \mathrm{He}$ detectors at the same scattering angle $2 \theta=90^{\circ}$ has been used. Detectors were equipped with $45^{\prime}$ Soller collimators. The cold moderator for the beamline 7A2 was in operation. During measurements the sample was rotated in $15^{\circ}$ incremental steps, and 14 sample positions have been measured, resulting in $14 \times 19=266$ neutron diffraction spectra. Measurement time at each sample position was 2 hours.

Neutron tomography experiments have been performed at the NEUTRA station (Lehmann et al. 2001) of the SINQ neutron source (PSI, Switzerland). The sample was subjected to a $25 \mathrm{meV}$ thermal neutron spectrum and the data were collected with a ${ }^{6} \mathrm{LiF}: \mathrm{ZnS}$ scintillator and a $2560 \times 2160$ Andor Neo sCMOS camera. The field of view was $105 \times 125 \mathrm{~mm}$. 625 projections around the sample have been measured for 3-D reconstruction with the exposure time of $70 \mathrm{~s}$ for each projection. The $3 \mathrm{D}$ object reconstruction has been performed using $49 \mu \mathrm{m}$ voxel size.

X-ray tomography experiments were performed on a NSI-X50 tomograph $(180 \mathrm{kV}$ beam voltage, $140 \mu \mathrm{A}$ electron current, tungsten target) at the Laboratoire de Méchanique et Technologie, ENS, Cachan. The sample was placed as close as possible to the Xray source to maximize the resolution on the $3000 \times 4000$ pixels flat panel detector. 1500 radiographs were acquired on the sample during a $3 \mathrm{hr}$ scan. The voxel size in the 3 -D reconstructed sample is $17.6 \mu \mathrm{m}$. 


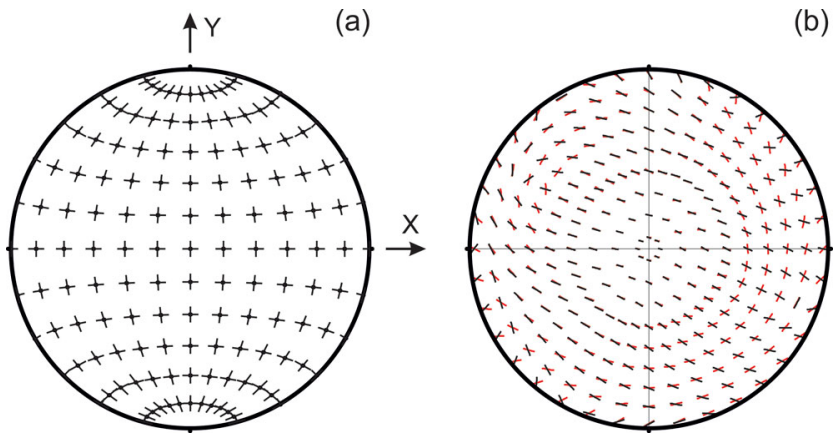

Figure 2. (a) Grid used during the ultrasonic measurements on the spherical sample. Dashes show the projected orientations of $S$-wave sensors (two $S$ sensors polarizations are perpendicular to each other). No measurements are possible in the $Y$ direction due to gears for the sample rotation. (b) Fast $S$-wave polarizations, as calculated from the elastic tensor inverted from measured set of velocities at a pressure of $100 \mathrm{MPa}$ (black) (see also Fig. 12b) and from the elastic tensor of the model Tambo gneiss with 0.1 vol.\% of micofractures parallel to muscovite grains and 0.6 vol. $\%$ of micofractures normal to foliation in lineation (red) (see also Fig. 12e). Equal area projection onto the foliation plane $(X Y)$ of the Tambo gneiss.

The measurements of $P$ - and $S$-wave velocities on the Tambo gneiss sample cube were carried out at pressures up to $400 \mathrm{MPa}$ in a multi-anvil pressure apparatus at the University of Kiel (Germany). The orientation of the cube was chosen with respect to macroscopic fabric elements, that is, edges of the cube are normal $(Z)$ and parallel to foliation $(X, Y)$ (Fig. 1b). We used the ultrasonic pulse transmission technique for the velocity measurements with transducers operating at $2 \mathrm{MHz}$ for $P$-waves and $1 \mathrm{MHz}$ for $S$ waves (e.g. Kern et al. 1997). Corresponding wavelengths are 3 and $4 \mathrm{~mm}$, respectively. The geometry of the piston-sample-transducer assembly allows simultaneous measurements of $V_{P}$ and $V_{S}$ in the three orthogonal directions of the sample cube, and direct determination of length changes (and, consequently, the volume change) with pressure. Shear wave splitting $\Delta V_{S}=V_{S 1}-V_{S 2}$ is measured by two sets of orthogonally polarized transducers with perpendicular polarization directions. Each set of experimental results is composed of three $P$-wave and six $S$-wave velocities. Length and resulting volume (density) changes, due to changes in principal stress, are obtained by the piston displacement (see Section 4).

Elastic wave velocities in the spherical sample have been measured by the pulsed ultrasonic method at pressures in the range of 0.1-400 MPa. The experiments have been carried out at the Laboratory of Physical Properties of Rocks, Institute of Geology of the CAS, v.v.i. using an improved design of Pros et al. (1998). The technical procedure of the measuring process is described in more detail by Lokajíček \& Svitek (2015). Resonant frequencies for $P$ - and $S$-wave sensors are 2 and $0.7 \mathrm{MHz}$, corresponding to wavelengths $1-3 \mathrm{~mm}$ and $1.5-5 \mathrm{~mm}$, respectively. Sensors are positioned along the surface of the sample in a regular $15^{\circ}$ grid, and placement of two orthogonally polarized $S$-wave sensors are along longitude and latitude of the spherical sample (Fig. 2a). So far, the capabilities to measure shear wave velocities are limited to pressures up to $100 \mathrm{MPa}$. Two measurements cycles have been done. In order to describe the closing process of microcracks, we first went up to the pressure of $400 \mathrm{MPa}$ with only $P$-wave sensors. Afterwards, a second measurement cycle has been performed with both $P$ and $S$ sensors at pressures 0.1 and $100 \mathrm{MPa}$.

\section{RESULTS}

\subsection{Microscopy}

The thin section analysis identified four major rock-forming minerals in Tambo gneiss: orthoclase, albite (extinction index e $=-5^{\circ}$, low refraction), quartz, and muscovite. Biotite, chlorite and pyrite are also present in minor quantities. Overall, the sample is a homogeneous muscovite gneiss.

Typical microstructures viewed in three orthogonal directions are presented in Fig. 3. Foliation (schistosity) is defined by the platy muscovite crystals exhibiting shape preferred orientation (SPO). The length of the muscovite platelets is in the range $0.2-0.8 \mathrm{~mm}$, their thickness perpendicular to foliation is about $0.1 \mathrm{~mm}$. Muscovite crystals are undeformed, that is optically they show uniform extinction, without bending or kinking. After metamorphic crystallization there was no significant deformation or alteration. The feldspar minerals (up to $0.8 \mathrm{~mm}$ ) are more or less equiaxed, whereas quartz (up to $0.5 \mathrm{~mm}$ ) is, at least in part, weekly flattened within the foliation plane and shows some undulatory extinction (Fig. 3a). Muscovite exhibits numerous low-aspect ratio intracrystalline cleavage cracks aligned parallel to the morphologic sheet plane (001) and some fractures parallel to grain boundaries (Figs 3a and b). Importantly, higher magnification figures reveal a second set of small microcracks, disposed subnormal to the cleavage plane (001) within muscovite grains (red arrows in Figs 3a and b). In contrast, twinned albite, orthoclase and quartz are almost free of intracrystalline fractures. These minerals exhibit mainly grain boundary fractures with more or less random orientation.

\subsection{Chemical composition}

Major elemental oxides contributing to the chemical composition of the Tambo gneiss are listed in Table 1. All the other chemical elements content is well below $0.1 \mathrm{wt} . \%$. The new measurements compare well with older data (Wenk et al. 1977). The major elements can be attributed to muscovite, plagioclase, alkali feldspar and quartz. Minor amounts of iron comes from pyrite and biotite, and phosphor from apatite.

\subsection{Neutron diffraction}

Three selected neutron diffraction spectra of the Tambo gneiss sample measured with the SKAT diffractometer are shown in Fig. 4 and some intensive diffraction peaks of rock-forming minerals are identified. All 266 recorded neutron diffraction spectra were processed simultaneously using the modified Rietveld refinement method implemented in the MAUD software (Lutterotti et al. 1997; Wenk et al. 2010a). The analysis of diffraction spectra confirms the microscopic observation that Tambo gneiss consists of the four major minerals: quartz, albite, orthoclase and muscovite (Table 2). Pyrite, biotite and apatite are 'invisible' on neutron diffraction spectra due to their low content ( $<1$ vol. $\%$ ).

The Rietveld refinement of diffraction data obtained from the polyphase rock requires the knowledge of the crystal structures of minerals composing this rock. For albite we used Downs et al. (1994), amcsd No. 0001683, for muscovite Catti et al. (1994), amcsd No. 0006533 and for orthoclase Tseng et al. (1995), amcsd No. 0007928. Note, that we changed structures of muscovite and orthoclase to monoclinic first setting for correct application of the texture refinement algorithm and for the texture-weighted averaging of single crystal elastic properties (Matthies \& Wenk 2009). But in this paper we present all the figures and Miller indices corresponding 

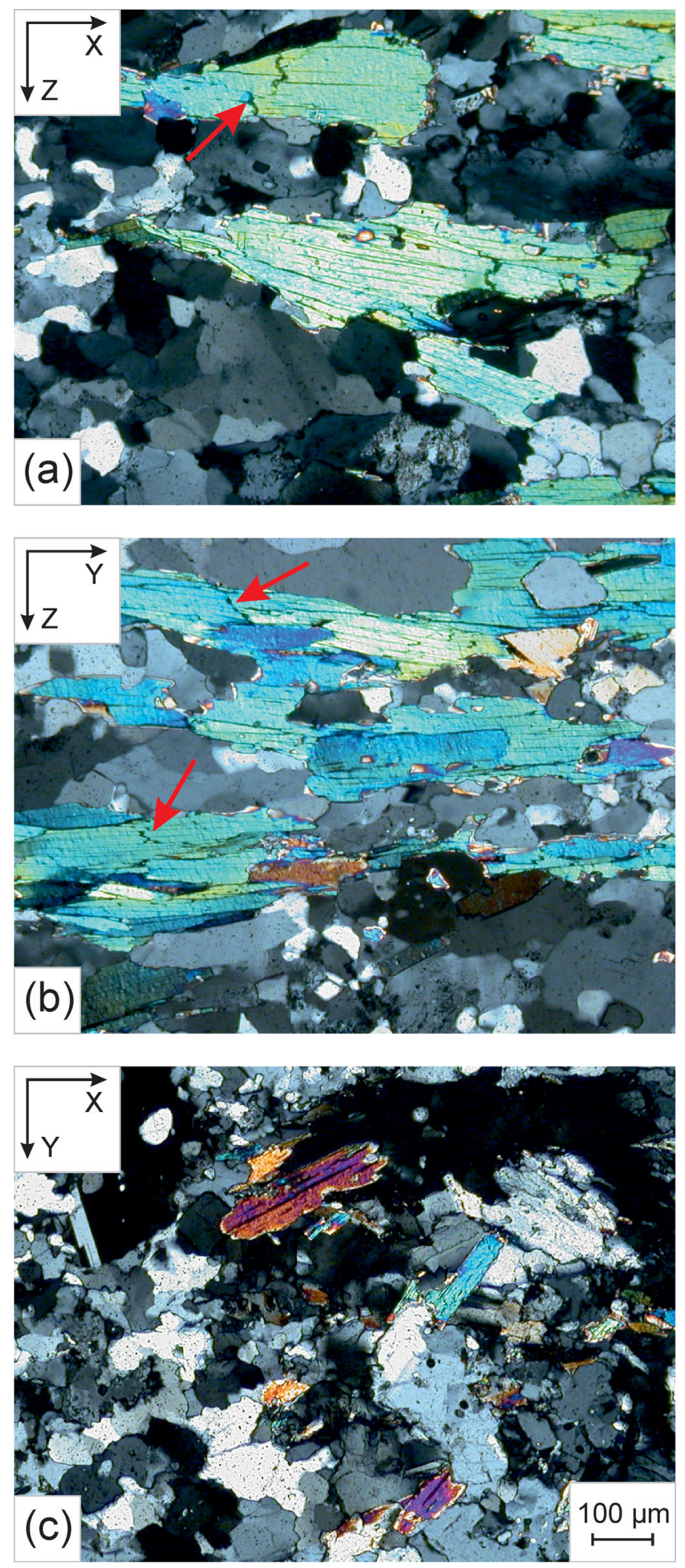

Figure 3. Petrographic thin sections of the sample illustrating the microstructure in different directions: (a) normal to $Y$ ( $X Z$ plane), (b) normal to $X$ (YZ plane), and (c) normal to $Z$ ( $X Y$ plane), all plotted in the same scale. $Z$ is normal to the foliation and $X$ is the lineation. Red arrows show intragranular cracks subnormal to muscovite cleavage cracks.

to the second monoclinic setting that is prevailing in mineralogy [with (001) corresponding to the cleavage plane of muscovite]. For $\alpha$-quartz we used Antao et al. (2008), amcsd No. 0006212, but we changed the structure and atomic positions to match the righthanded space group $\mathrm{P} 3{ }_{1} 21$.
In MAUD, some crystallographic and microstructural characteristics of minerals have been refined, in addition to mineral volume fractions and crystallographic preferred orientations (CPO) (Table 2). To refine CPO a direct E-WIMV (Matthies 2002; Lutterotti et al. 2004) algorithm has been used with $7.5^{\circ}$ resolution in orientation space. For the refinement a range in lattice spacings $d=1.4-5.1 \AA$ was used. Fig. 4 also shows calculated diffraction spectra (solid lines) in addition to observed diffraction spectra (dotted pattern). The agreement between measured and refined spectra is very good, reflecting the high reliability of the refinement parameters. This is also expressed in a low weighted profile reliability factor (Toby 2006) $R_{\mathrm{wp}}=6.9$ per cent.

After the refinement, orientation distribution functions (ODFs) of all minerals have been exported into the BEARTEX software (Wenk et al. 1998), and smoothed with a $7.5^{\circ}$ Gaussian filter. From these smoothed ODFs, some pole figures of all major phases have been recalculated (Fig. 5). General information on refined mineral composition and crystallographic textures is summarized in Table 2. The Tambo gneiss contains 82.5 vol. $\%$ of quartz and feldspars that demonstrate fairly weak preferred orientations with texture indices $\mathrm{F}_{2}$ (Bunge 1982) close to 1 . Quartz displays a weak but regular pattern with c-axes distributed in a crossed girdle pattern (e.g. Sander 1950, p. 363) and a $\{10 \overline{1} 1\}$ maximum normal to the foliation (Fig. 5a). The feldspar pole figures are more irregular which may be due to limited grain statistics (Figs $5 \mathrm{~b}$ and c). Very low minimum (almost zero) and high maximum ODF values are recorded for albite. These are most likely artefacts appearing because of difficulties in the deconvolution of peak overlaps for this triclinic mineral. Muscovite (17.5 vol.\%) has a strong and regular preferred orientation with a (001) maximum (second monoclinic setting) normal to foliation (17 multiples of a random distribution); (100) and (010) normals are distributed within the foliation plane and show no apparent alignment (Fig. 5d, note that logarithmic pole density scale is used).

The determination of precise composition of feldspars in the Tambo gneiss using SKAT data is impossible due to inadequate resolution and neutron flux. Unit cell parameters (Table 2), though, may be used as an indirect measure of the plagioclase composition, as they demonstrate a regular behaviour with increase in anorthite content (e.g. Bambauer et al. 1967). The difference between unit cell parameters of plagioclase feldspar in Tambo gneiss and those of the pure low albite is consistent with a slightly increased An content corresponding to $\sim$ An 8 . This is also supported by the bulk chemical composition data (Table 1) that indicates the presence of a small amount of calcium oxide. The same applies to potassium feldspar in the Tambo gneiss that is likely different from pure orthoclase, containing some sodium.

\subsection{Neutron computed tomography}

Fig. 6(a) shows a slice through the reconstructed tomography data sets acquired using neutrons. The brighter a feature appears in the reconstructed computed tomography data the higher is the corresponding attenuation coefficient.

Most of the sample is composed of feldspars and quartz containing elements that all show rather low neutron attenuation coefficients. But mica contains hydrogen in the crystal lattice that has a very high incoherent scattering cross section. Thus, we attribute most features of the sample with high attenuation to mica. Platy muscovite grains are visible as brighter inclusions in Fig. 6, often overlapping and forming layers parallel to the foliation. 
Table 1. Chemical composition of the Tambo gneiss sample (in wt.\%). All the other elements content is well below $0.1 \mathrm{wt} . \%$. New analyses are compared with two samples from Wenk et al. (1977).

\begin{tabular}{|c|c|c|c|c|c|c|c|c|c|}
\hline Oxide & $\mathrm{Na}_{2} \mathrm{O}$ & $\mathrm{MgO}$ & $\mathrm{Al}_{2} \mathrm{O}_{3}$ & $\mathrm{SiO}_{2}$ & $\mathrm{P}_{2} \mathrm{O}_{5}$ & $\mathrm{~K}_{2} \mathrm{O}$ & $\mathrm{CaO}$ & $\mathrm{TiO}_{2}$ & $\mathrm{Fe}_{2} \mathrm{O}_{3}$ \\
\hline Tambo gneiss, this study & 4.1 & 0.27 & 17.1 & 71.4 & 0.30 & 4.9 & 0.58 & 0.11 & 1.05 \\
\hline Standard error & 0.1 & 0.03 & 0.2 & 0.2 & 0.03 & 0.1 & 0.04 & 0.02 & 0.05 \\
\hline Sci 62, Promontogno & 3.15 & 0.3 & 14.6 & 73.3 & 0.24 & 4.85 & 0.95 & 0.16 & 1.15 \\
\hline
\end{tabular}

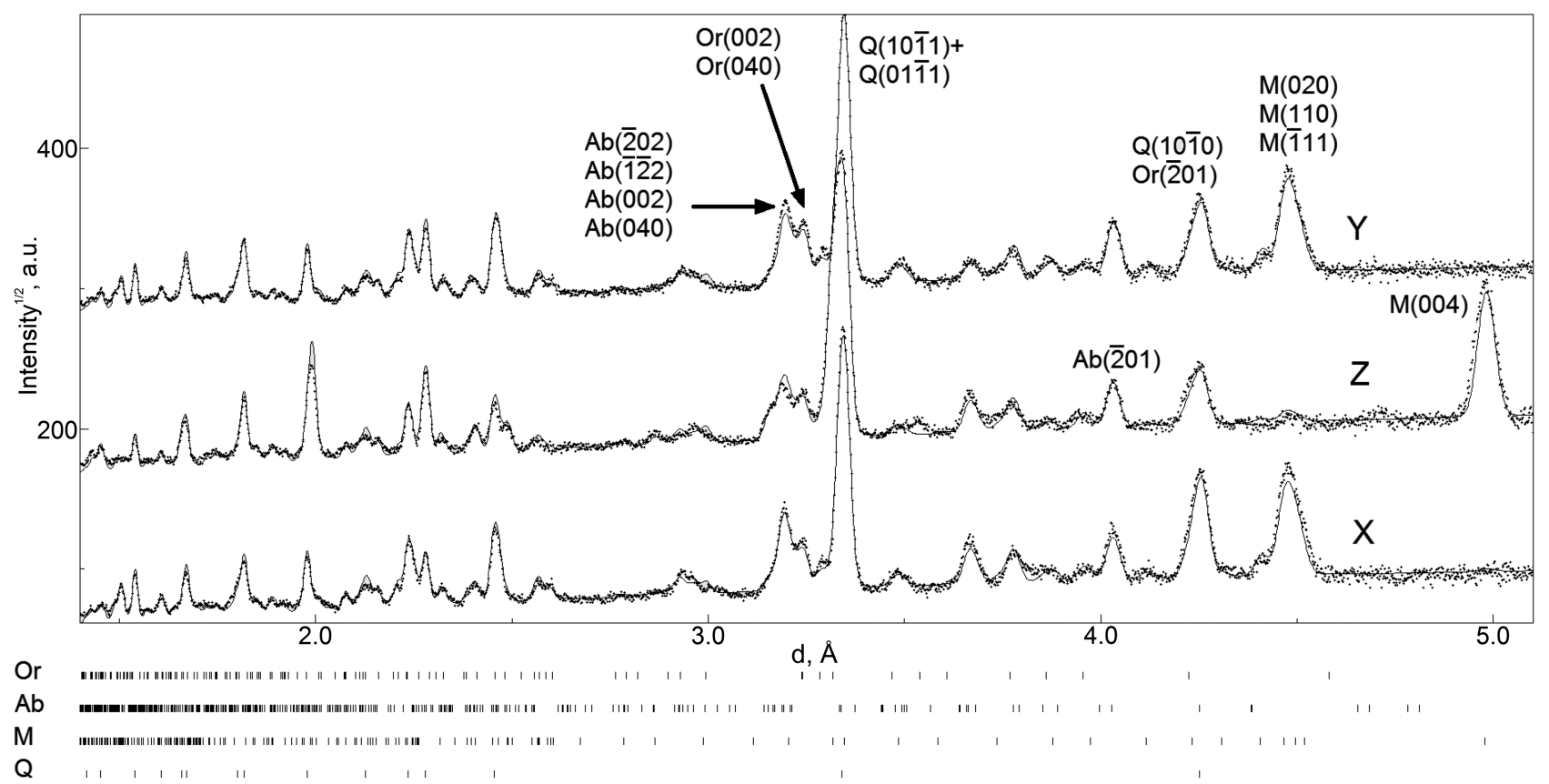

Figure 4. Selected neutron diffraction spectra of Tambo gneiss sample, measured on SKAT diffractometer with scattering vector directions parallel to different axes of the Cartesian coordinate system $\{\mathrm{X}, \mathrm{Y}, \mathrm{Z}\}$. Dots are measured data, and lines are the result of the refinement. Diffraction peak positions of major minerals composing the sample ( $\mathrm{Or}$ - orthoclase, $\mathrm{Ab}$ - albite, $\mathrm{M}$ - muscovite, $\mathrm{Q}$ - quartz) are shown below. Some of the most intensive diffraction peaks are indexed (second monoclinic setting is used for muscovite and othoclase).

Table 2. Mineral volume fractions, minimum and maximum values (in m.r.d.) on pole figure (001), texture index $F_{2}$ and refined unit cell parameters for minerals composing the Tambo gneiss sample. Statistical errors for the last digits are given in parentheses. Values for muscovite and orthoclase are given in the second monoclinic setting.

\begin{tabular}{lllll}
\hline Phase & Quartz & Albite & Orthoclase & Muscovite \\
\hline Volume fraction (per cent) & $38.7(2.6)$ & $25.8(1.7)$ & $18.0(1.2)$ & $17.5(1.2)$ \\
$(001)$ min. & 0.4 & 0.5 & 0.6 & 10.0 \\
$(001)$ max. & 1.7 & 2.5 & 1.5 & 0.1 \\
$F_{2}$ & 1.2 & 1.3 & 1.1 & 3.6 \\
$a(\AA)$ & $4.91057(2)$ & $8.1374(1)$ & $8.5808(2)$ & $5.2071(1)$ \\
$b(\AA$ & $4.91057(2)$ & $12.7887(3)$ & $12.9570(4)$ & $9.0388(1)$ \\
$c(\AA)$ & $5.40302(4)$ & $7.1502(1)$ & $7.1994(2)$ & $20.0069(3)$ \\
$\alpha\left({ }^{\circ}\right)$ & 90 & $94.024(3)$ & 90 & 90 \\
$\beta\left(^{\circ}\right)$ & 90 & $116.559(2)$ & $115.840(2)$ & $95.575(2)$ \\
$\gamma\left({ }^{\circ}\right)$ & 120 & $87.902(3)$ & 90 & 90 \\
\hline
\end{tabular}

Fig. 6(b) shows the sectioned 3-D visualization of the reconstructed neutron tomography of Tambo gneiss sphere. The surface of the sample shows very high scattering. This is most likely due to the epoxy layer containing hydrogen (that was spread on the surface of the sample for the high pressure ultrasonic experiments with oil as a pressure medium and was not completely removed). Thus for the further quantitative analysis we used only the inner part of the spherical sample with a $2 \times 2 \times 2 \mathrm{~cm}^{3}$ volume shown at Fig. 6(c). It was analysed with the Avizo software by FEI Visualization Sciences Group (Mérignac, France), extracting the features of inclusions we considered to be mica grains.
The average aspect ratio of mica was estimated as 0.6. This number is of the same order as the aspect ratio estimation based on optical microscopy results (between 1 and 1:6 in $X Z$ and $Y Z$ sections and about $1: 1$ in $X Y$ section, Fig. 3). Mica grains have a preferred orientation with platelets within the foliation plane, which qualitatively agrees with the results of neutron diffraction texture analysis. All images (Figs 6a-c) of Tambo gneiss display layers that are relatively enriched in muscovite (bright), probably the cause for the excellent cleavage, and layers with lower muscovite content (dark). On average, thickness of such bright layers is about $0.5 \mathrm{~mm}$. Pores and fractures are invisible for the neutron tomography due to 
(a)
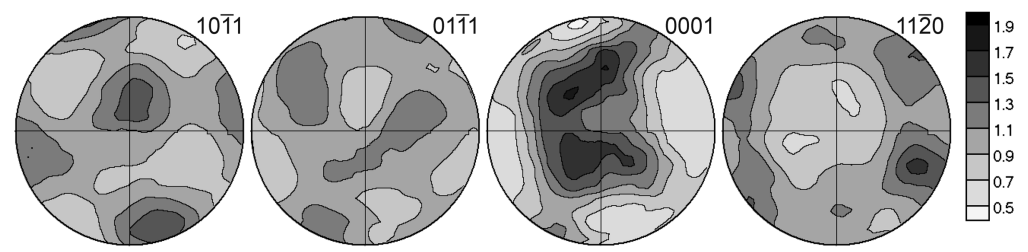

(b)

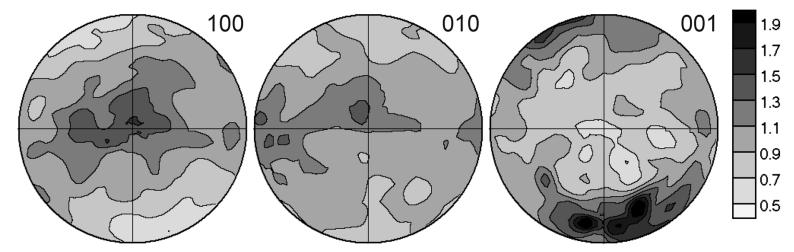

(c)

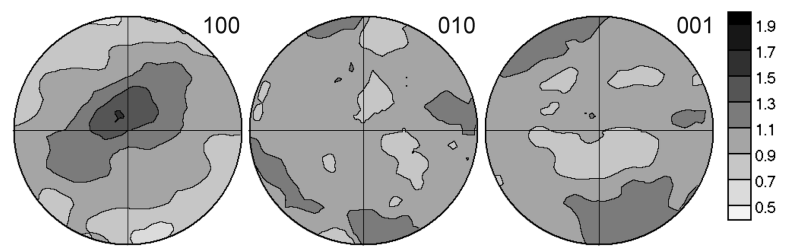

(d)
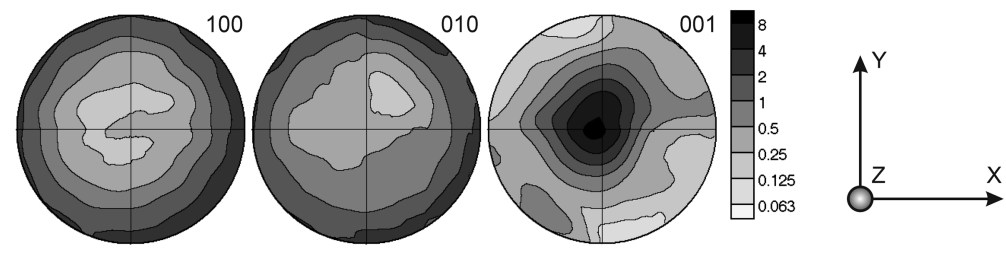

Figure 5. Pole figures of quartz (a), albite (b), orthoclase (c) and muscovite (d) in Tambo gneiss sample. Equal area projections and pole densities in multiples of random distribution. A linear scale is used for all plots, except for muscovite (d) where a logarithmic scale is used. Structure coordinate $X Y Z$ system is also shown. All the subsequent projections are plotted in the same coordinate system.
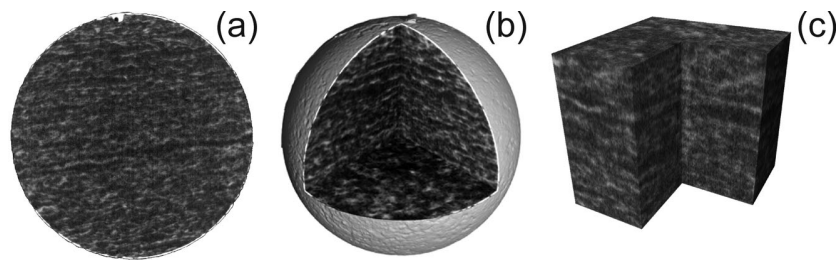

Figure 6. Neutron tomography data: $X Z$ slice through the spherical $(5 \mathrm{~cm}$ in diameter) Tambo gneiss sample (a), a section of the spherical sample (b), and a central part of the spherical sample $\left(2 \times 2 \times 2 \mathrm{~cm}^{3}\right.$ cube $)$ used for the analysis (c). White colour means higher attenuation. (a)

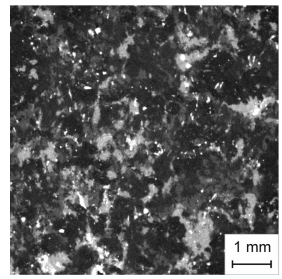

(b)

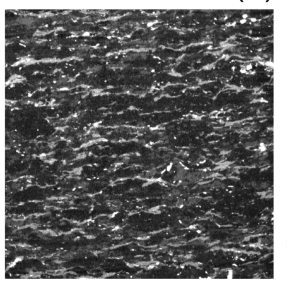

(c)

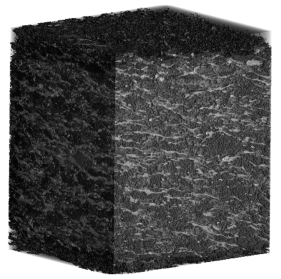

Figure 7. X-ray tomography data: a part of XY slice (a), a part of XZ slice (b), and a 3-D reconstruction of the $\approx 2 \times 2 \times 2 \mathrm{~cm}^{3}$ sample (c). The scale in (a) and (b) is the same. White colour means higher attenuation.

their low thickness that is below the resolution level (i.e. less than $50 \mu \mathrm{m}$ thick).

\subsection{X-ray computed tomography}

Some of the X-ray tomography results are presented in Fig. 7. Brighter features of the figure again mean higher attenuation. Also for X-rays muscovite has higher X-ray attenuation than quartz and feldspar, due to higher density, and X-ray imaging results can be directly compared to neutron tomography. Brightest small features of roughly spherical or cubic shape present in Fig. 7 correspond to pyrite $\mathrm{FeS}_{2}$ inclusions that were not detected by neutron diffraction and neutron imaging. The analysis of images was performed using the 3D Roi Manager tool (Ollion et al. 2013).

2-D slices through the X-ray computed tomography data set (Figs 7a and b) as well as 3-D reconstruction (Fig. 7c) confirm the platy shape of muscovite grains (with the average aspect ratio of $\sim 0.4$ ) and their SPO with preferred orientation of platelets close to the foliation plane. Also X-ray tomography suggests that muscovite platelets are arranged in layers (Fig. 7b). Occasionally, some roughly equiaxed features with very low X-ray attenuation are visible within the sample. Their typical size is $50-150 \mu \mathrm{m}$. They can be associated with 'spherical' porosity present in the sample, but their volume fraction is extremely low: $<0.05$ vol. $\%$. Thin intracrystalline fractures (Fig. 3) are not detected by X-ray tomography, indicating that their thickness is below the resolution of the reconstructed 3-D image $(\sim 17 \mu \mathrm{m})$.

\subsection{Sample compaction and density estimations}

The initial (at $0.1 \mathrm{MPa}$ pressure) density of the cube sample prepared for ultrasonic measurements was $2641 \mathrm{~kg} \mathrm{~m}^{-3}$. From the piston displacement of the multi-anvil pressure apparatus (Fig. 8) it is possible to estimate the volume compaction and assess density values at higher pressures. Sample compaction is highest normal to foliation (parallel Z) mainly due to significant compaction of low-aspect ratio microcracks aligned parallel to the morphologic sheet plane (001) of oriented muscovite grains (see also Melendez-Martinez \& 


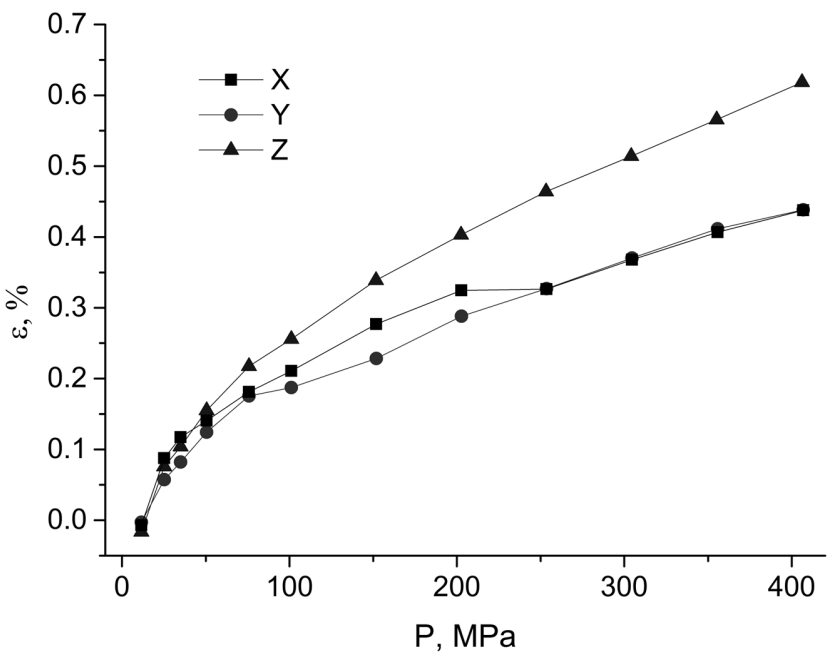

Figure 8. Relative piston displacements in different structural directions $(X$, $Y$ and $Z$ ) of Tambo gneiss cube sample at pressures up to $400 \mathrm{MPa}$.

Schmitt 2016 and Ong et al. 2016). The higher deformation in the $\mathrm{Z}$ direction may also be partially caused by preferential compaction of the muscovite structure in the direction perpendicular to the layered crystal structure (weaker bonding direction).

Linear strain at $406 \mathrm{MPa}$ as derived from the piston displacements is 0.62 per cent in the $\mathrm{Z}$ direction and 0.44 per cent in the $\mathrm{Y}$ and $\mathrm{X}$ directions. The corresponding volume compaction, representing mainly the crack-related porosity, is about 1.50 per cent. Consequently, the density value at $406 \mathrm{MPa}$ pressure could be estimated as $2681 \mathrm{~kg} \mathrm{~m}^{-3}$.

The density of the spherical sample (estimated using its measured mass and an average diameter based on probes in 30 different directions) is $2635 \mathrm{~kg} \mathrm{~m}^{-3}$. If we use density values determined by single crystal elastic constants measurements for quartz (Heyliger et al. 2003), albite (Brown et al. 2006), orthoclase (Waeselmann et al. 2016) and muscovite (Vaughan \& Guggenheim 1986) and refined mineral composition (Table 2), then resulting Tambo gneiss density would be $2658.6 \mathrm{~kg} \mathrm{~m}^{-3}$. The density derived from corresponding crystal structures of minerals, and their refined cell parameters and volume fractions is $2664.6 \mathrm{~kg} \mathrm{~m}^{-3}$. The difference between these density values is about \pm 1 per cent and the uncer- tainty introduced into calculated elastic wave velocities is about \pm 0.5 per cent, which is at the limit of the resolution of elastic wave velocities measurements. For simplicity, in our calculations, modelling and elastic tensor inversions we will use a density value of $2635 \mathrm{~kg} \mathrm{~m}^{-3}$.

\subsection{Ultrasonic measurements on the cube sample}

The measurements of both longitudinal and shear wave velocities were done at room temperature over a range of pressures from 11 up to $406 \mathrm{MPa}$. The effect of pressure on $V_{P}$ and $V_{S}$ is illustrated in Figs 9(a) and 10, respectively, along with corresponding velocity anisotropy of $P$ waves $\left(\mathrm{A}-V_{P}\right)$. Anisotropy is defined by the percent differences between maximum and minimum velocity with respect to mean velocity (Birch 1961). Here, to keep consistency and to be able to make a comparison between two different ultrasonic measurement methods, we define the anisotropy coefficient A- $V_{P}[\%]$ as $100^{*}\left(V_{P \max }-V_{P \text { min }}\right) / V_{P \text { mean }}$, where $V_{P \text { mean }}=\left(V_{P X}+V_{P Y}+V_{P Z}\right) / 3$, and both $V_{P \max }$ and $V_{P \min }$ are selected from the set of three velocities $\left\{V_{P X}, V_{P Y}, V_{P Z}\right\}$ only. In the similar manner, anisotropy coefficients for fast and slow $S$ wave could be defined.

The initial non-linear rise on the curves in Figs 9(a) and 10 is due to fast progressive closure of microcracks, documenting the pressure sensitivity of $P$ and $S$ waves. The quasi-linear part of the curves (200-400 MPa) reflects mainly the intrinsic rock properties that are basically controlled by the volume percentage of major minerals, their single crystal elastic properties and their crystallographic preferred orientations (CPOs).

The differences of $P$-wave velocities measured in the three structural directions $X, Y$ and $Z$ indicate marked velocity anisotropy (Fig. 9a). Highest velocities are measured parallel to foliation (XYplane) and lowest normal to foliation $(Z)$. Anisotropy $\left(\mathrm{A}-V_{P}\right)$ is highest at low pressure due to the constructive superposition of the effects of oriented microcracks and CPO of the rock-forming minerals. Increasing pressure reduces the effect of the cracks and the residual (intrinsic) anisotropy is mainly due to CPO. At maximum pressure the anisotropy coefficient $\mathrm{A}-V_{P}$ is 9.6 per cent, while at pressures below $30 \mathrm{MPa}$ it is close to 27 per cent.

Shear wave splitting $\left(\Delta V_{S}=V_{S 1}-V_{S 2}\right)$, which is also an important diagnostic phenomenon of anisotropy, is observed parallel to $\mathrm{X}$ and $\mathrm{Y}$ within the foliation plane, with the fast split shear wave being polarized parallel to foliation (Fig. 10). Normal to the foliation, there is practically no shear wave splitting observed (Fig. 10c).
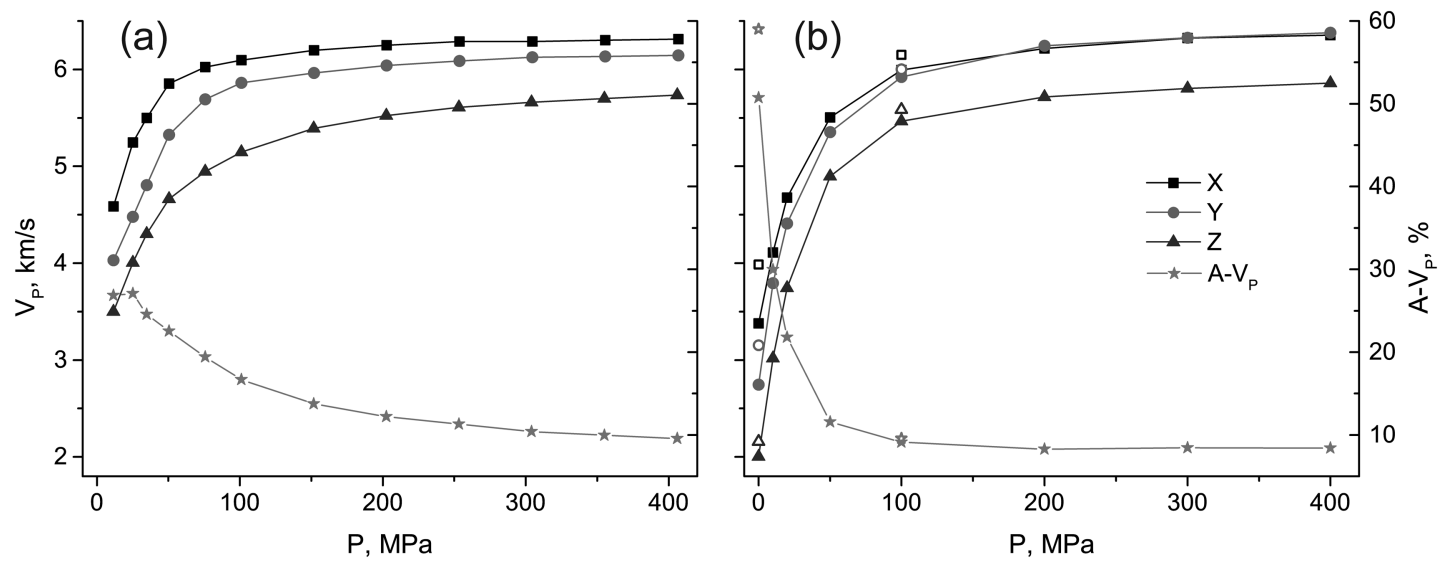

Figure 9. $P$-wave velocities in structural directions $X, Y$ and $Z$ of the Tambo gneiss sample at different confining pressures up to $400 \mathrm{MPa}$. (a) phase velocities measured on cube, and (b) group velocities measured on sphere. Anisotropy coefficient A- $V_{P}$ is also shown (right axis). Open symbols on plot (b) refer to the second run. 

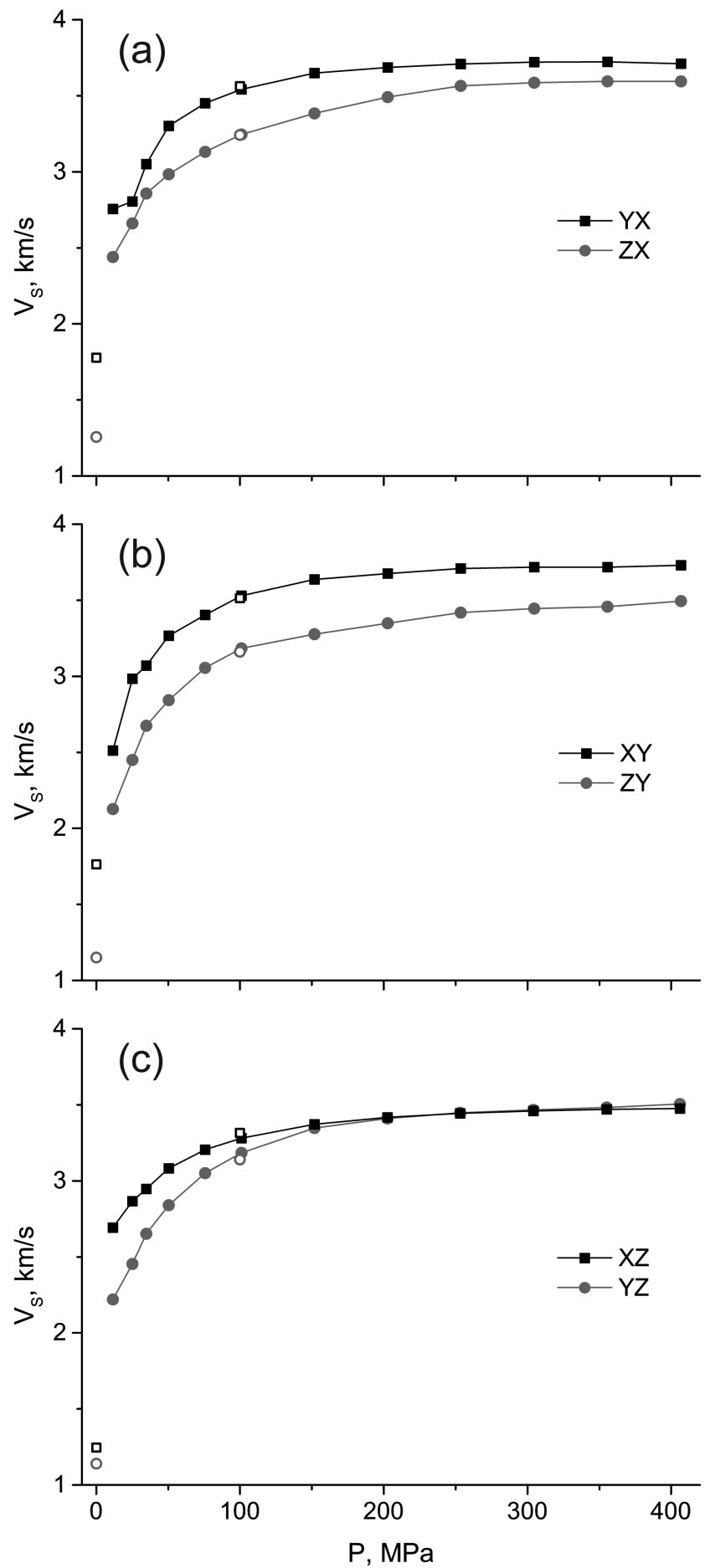

Figure 10. Shear elastic wave velocities in structural directions $X$ (a), $Y$ (b) and $Z$ (c) of the Tambo gneiss sample at different confining pressures. Measurements to $400 \mathrm{MPa}$ on cube (filled symbols) refer to phase velocities, and measurements at $100 \mathrm{MPa}$ on sphere (open symbols) refer to group velocities (sphere, second run).

This direction marks a singularity, that is, $S$ waves propagate in this direction like in an isotropic medium, that is almost transverse isotropy.

The apparent isotropic Poissons's ratio (at $406 \mathrm{MPa}$ pressure) as derived from the arithmetic mean of $\mathrm{V}_{P}$ and $\mathrm{V}_{\mathrm{S}}$ measured in $X, Y$ and $Z$ is 0.23 . This relatively low Poisson's ratio reflects the high mineral fraction of quartz that has an extremely low Poisson's ratio $(\approx 0.06$ for an isotropic quartz aggregate, as can be calculated from elastic coefficients, Heyliger et al. 2003) compared to feldspars and mica.

The $V_{P}$ and $V_{S}$ velocity values satisfy the relation $V[X] \approx V[Y]>$ $V[Z]$ that points to a roughly transversely isotropic material fabric with $Z$ as the symmetry axis.

\subsection{Ultrasonic measurements on the spherical sample}

As mentioned earlier, two ultrasonic measurement runs were performed on a spherical sample, first with only $P$ waves, second with both $P$ and $S$ waves. Dependencies of $P$-wave velocities on pressure in main structural directions $X, Y$ and $Z$ are summarized in Fig. 9(b), and $S$-wave velocities (from the second experimental run) are shown in Fig. 10 (open symbols). One drawback of the ultrasonic system is that no measurements are possible in the $Y$-direction, as this is where two gears for the sample rotation are fixed. To assess the $V[Y]$ velocities we inverted the measured set of velocities into the stiffness tensor of the Tambo gneiss, using the method of Svitek et al. (2014). No sample symmetry is imposed, and we obtained 21 elastic parameters, from which we are able to calculate phase velocities of longitudinal and shear waves at any required direction together with shear-wave splitting.

It should be noted, that group (or ray) velocities are measured by the high pressure ultrasonic system. Since the inversion of phase velocities is more convenient and can be realized in a relatively simple way through the Christoffel equation, measured group velocities are recalculated into the phase velocities (Svitek et al. 2014). After this step, we inverted longitudinal and (if available) shear wave phase velocities to obtain a full elastic tensor of 21 elastic parameters. In the inversion, we apply perturbation theory in an iterative manner (Klíma 1973). For Tambo gneiss, measured elastic wave velocities match those calculated from the inverted elastic tensor within $0.1 \mathrm{~km} \mathrm{~s}^{-1}$ error.

Fig. 9(b) demonstrates that elastic $P$ waves in the $Z$ direction are slower than those in the foliation plane. The initial rapid increase of velocity values at pressures up to $100-200 \mathrm{MPa}$ can be attributed to the closure of pores and fractures. There are no significant differences in $P$-wave velocities at pressures 200, 300 and $400 \mathrm{MPa}$. Also, $P$-wave velocities in $X$ and $Y$ directions are almost equal at pressures above $200 \mathrm{MPa}$ (compared with a significant difference of $\approx 0.8 \mathrm{~km} \mathrm{~s}^{-1}$ at $0.1 \mathrm{MPa}$ ). This is consistent with nearly transverse isotropy of the material at increased pressures.

Fig. 11 shows some of the $P$-wave velocity distributions, obtained on a spherical sample during the first experimental run. At a pressure of $0.1 \mathrm{MPa}$ the distribution is close to orthorhombic, and the maximum velocity direction is close to but does not coincide with the assumed lineation $(X)$. Already at a hydrostatic pressure of $200 \mathrm{MPa}$ the velocity distribution in the sample is very close to axially symmetric (transverse isotropy).

Comparing experimental run 1 and run 2 we note (Fig. 9b) that $P$ wave velocity values for run 2 are always larger. Normal to foliation ( $Z$ direction) the difference between run 1 and run 2 velocities is rather small. In the $X$ direction the difference between run 1 and run 2 is larger, especially at lower pressures $\left(0.61 \mathrm{~km} \mathrm{~s}^{-1}\right.$ at $\left.0.1 \mathrm{MPa}\right)$.

We also note that between two shear waves propagating in the foliation plane, the wave polarized in the foliation $X Y$ is always faster (Fig. 10). Shear wave splitting in the $Z$ direction is low; the fast $S$ wave propagating in $Z$ is polarized close to direction $X$.

Velocity distributions (both $P$ and $S$ waves) obtained during the second experimental run on a spherical sample by inversion of all 


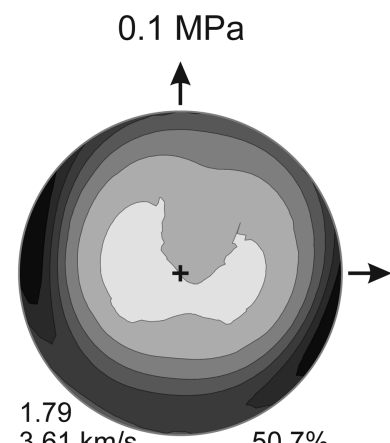

$3.61 \mathrm{~km} / \mathrm{s}$

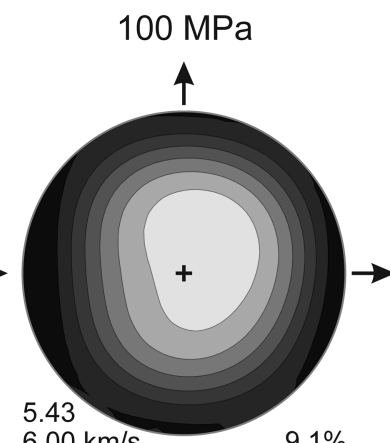

$9.1 \%$

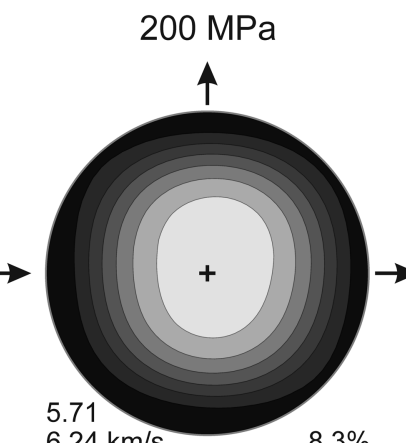

$6.24 \mathrm{~km} / \mathrm{s}$

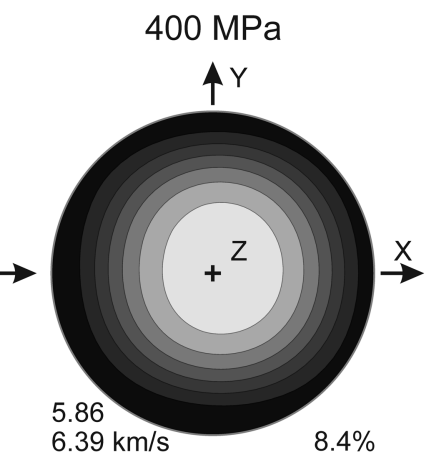

$8.4 \%$

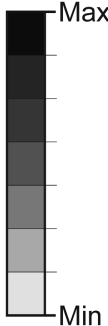

$.39 \mathrm{~km} / \mathrm{s}$ data (Svitek et al. 2014), are shown in Figs 12(a) and (b). In this run, the symmetry of the $P$-wave velocity distribution at $100 \mathrm{MPa}$ does not change compared to $0.1 \mathrm{MPa}$ pressure; only the values of velocities do increase with pressure, and the anisotropy coefficient decreases from a very high value of 59.0 per cent to a moderate 9.6 per cent. Maximum $V_{P}$ indeed lies in the foliation plane, but does not coincide with the lineation direction $X$. The symmetry of $V_{S 1}$ distribution at $0.1 \mathrm{MPa}$ pressure is closer to axially symmetric. It is more orthorhombic at $100 \mathrm{MPa}$, and maximum $V_{S 1}$ value directions do not coincide with structural directions $X, Y, Z$ (though they remain in the foliation plane $X Y$ ). As the pressure increases from 0.1 to $100 \mathrm{MPa}$, polarization directions of fast $S$ waves $V_{S 1}$ (indicated by red lines in Figs 12a and b) do not change for waves propagating in directions normal to the direction of the fastest $P$-wave that is in the foliation plane and tilted about $25^{\circ}$ to the lineation. In other directions, wave polarizations corresponding to $V_{S 1}$ change considerably, sometimes by almost $90^{\circ}$, meaning effectively a swap in order of $V_{S 1}$ and $V_{S 2}$ velocities. In general $V_{S 1}$ polarizations (Figs $12 \mathrm{a}$ and $\mathrm{b}$ and Fig. 2b) are different from the $S$-wave sensor orientations (Fig. 2a). Indeed, if the incident shear wave is polarized parallel to the orientation of the sensor, shear wave onset is very well pronounced on the registered signal. In other cases, shear waves registered on the receiver have lower amplitude but are still detectable. However, this fact is not crucial, regarding to the overall quality of the inversion process as shown by synthetic tests (Svitek et al. 2014).

$\mathrm{V}_{S 2}$ distributions are nearly isotropic; the difference between minimum and maximum $V_{S 2}$ values is only $0.2 \mathrm{~km} \mathrm{~s}^{-1}$ at $0.1 \mathrm{MPa}$ pressure and $0.27 \mathrm{~km} \mathrm{~s}^{-1}$ at $100 \mathrm{MPa}$. Though rather irregular at $0.1 \mathrm{MPa}$, at $100 \mathrm{MPa}$ pressure the symmetry of $V_{S 2}$ distributions becomes close to orthorhombic, and the maximum $\mathrm{V}_{S 2}$ direction does not coincide with any of the $X, Y, Z$ directions.

\section{MODELS OF BULK ELASTIC PROPERTIES}

To model bulk elastic properties of Tambo gneiss we used a modified self-consistent method GeoMIXself (GMS) developed by Matthies (2010, 2012). It combines the standard self-consistent routines (e.g. Morris 1970) with elements of the geometric mean model GEO (Matthies \& Humbert 1995). The GMS method is able to take into account CPO, morphologies and SPOs of grains. This is an advance compared to often used (due to their relative simplicity and clear physical interpretation) Reuss and Voigt models. The Voigt model is based on the 'equal strain' assumption and represents the upper boundary for the stiffness of the polycrystalline body. The
Reuss model assumes 'equal stress' state and is the lower stiffness boundary. Due to the application of GEO elements, GMS algorithm provides a unique solution for the elastic properties of the effective medium representing the polycrystalline material. It does not take effects of layering into account.

Another advantage of the GMS method is that pores/cracks existing in the material can be considered as inclusions with zero stiffness. Since the work of Walsh (1965), many models were proposed considering the influence of cracks, fractures or pores on the elastic properties of rocks, including self-consistent schemes (e.g. O'Connell \& Budiansky 1974), differential effective medium models (e.g. Hornby et al. 1994), very popular 'second order in cracks density' models (e.g. Hudson 1980), and recently finite element calculations (e.g. Yoneda \& Sohag 2011). Details on the development of these model and their applicability are summarized in several reviews (e.g. Kachanov 1993; Grechka \& Kachanov 2006). As shown by Sayers \& Kachanov (1991), the description of the cracked material with self-consistent, differential effective medium and non-interacting methods provide essentially similar results for crack densities below 5 per cent, which is true for a gneiss rock with a very low porosity that we study in this paper. Thus we model first the crack-free material - Tambo gneiss - and then add cracks into it within the same GMS algorithm.

Single crystal elastic properties of minerals are one of the necessary components for the bulk elastic properties model of polycrystalline rock. Here we use elastic tensors measured by Heyliger et al. (2003) for quartz and by Vaughan \& Guggenheim (1986) for muscovite. We specifically note that the latter needs to be changed to first monoclinic setting to comply with the CPO analysis. We use albite properties (from Brown et al. 2006, see also Kaercher et al. 2014; Brown et al. 2016) changing it to comply with a right-handed Cartesian crystal coordinate system $K_{\mathrm{B}}$ used in texture analysis $\left(K_{\mathrm{B}}\right.$ is set with $Z_{\mathrm{B}}$ parallel to crystal translation $c, Y_{\mathrm{B}}$ is normal to $c$ and $a$ : $Y_{\mathrm{B}} \| b^{*}=c \times a$, and $\left.X_{\mathrm{B}}=Y_{\mathrm{B}} \times Z_{\mathrm{B}}\right)$. For orthoclase we used data of (Waeselmann et al. 2016) that were obtained for the $\mathrm{Or}_{93} \mathrm{Ab}_{7}$ feldspar (also changing to first monoclinic setting). Single crystal constants that we use are summarized in Table 3.

To take into account the influence of non-spherical grain shapes of a given mineral (e.g. muscovite) on bulk elastic properties of the whole rock it is necessary to know the shape orientation distribution for this mineral. As discussed by Vasin et al. (2013), for sheet silicates characterized by platelet-shaped grains it is easy to obtain shape orientation distributions (SPO) from the CPO. This is done by considering an additional rotation in the ODF, and also taking this rotation into account for the coordinate system in which the 
(a)

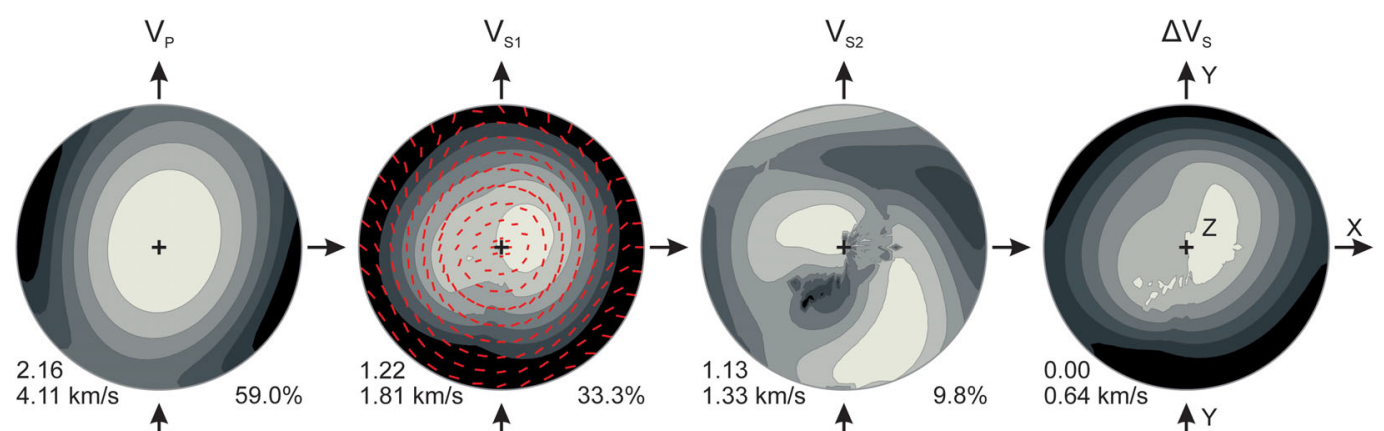

(b)

(c)

(d)

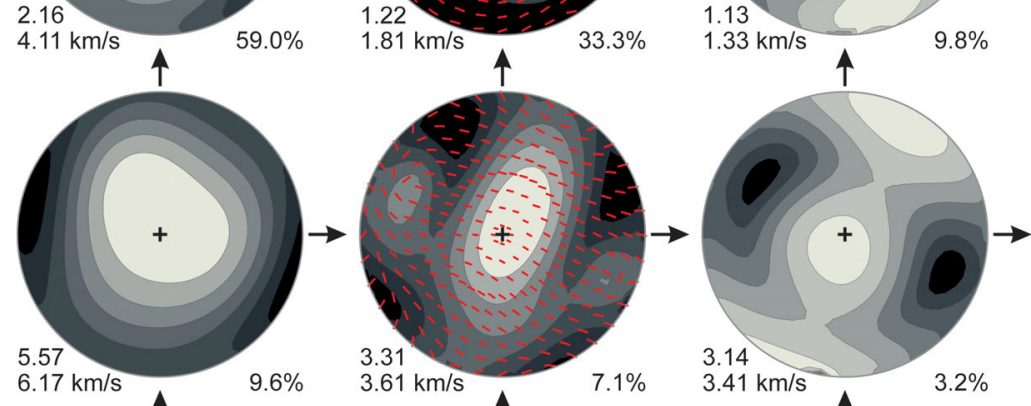

$0.64 \mathrm{~km} / \mathrm{s} \uparrow \mathrm{Y}$

(f)
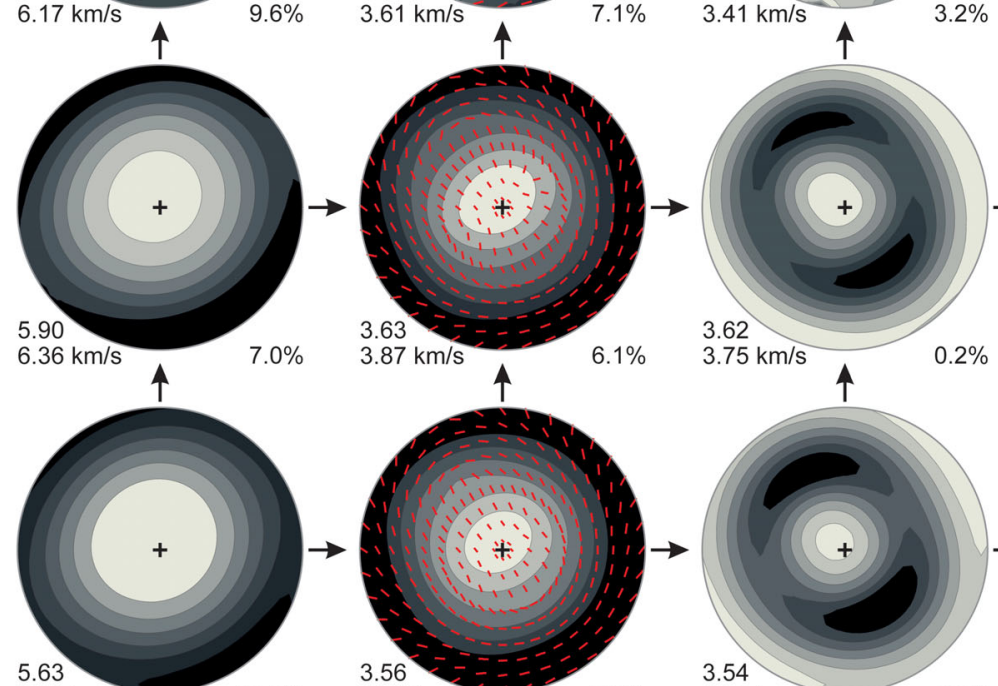

$0.2 \%$

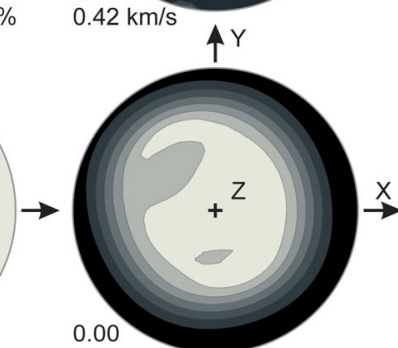

$0.25 \mathrm{~km} / \mathrm{s}$
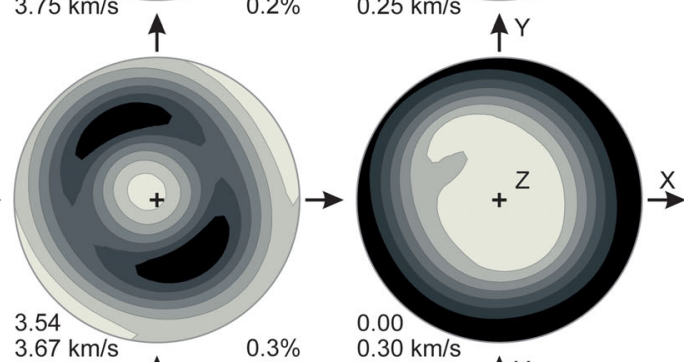

$0.00 \mathrm{~km} / \mathrm{s}$

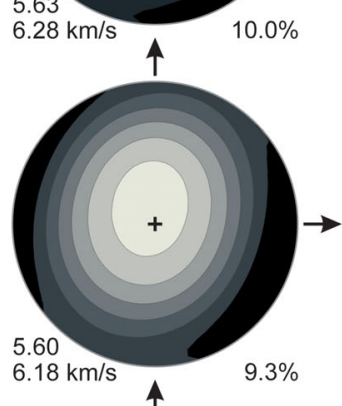

$\uparrow$
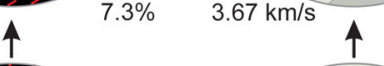

$0.3 \%$
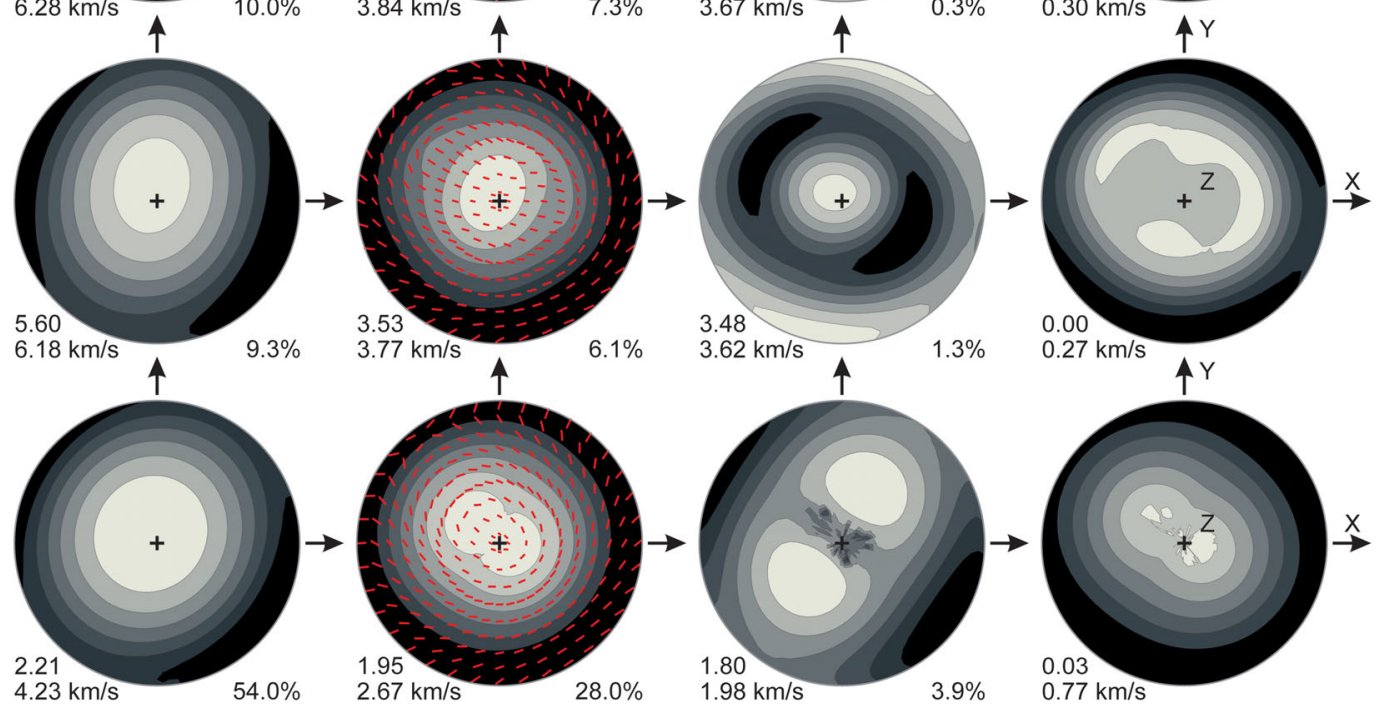

Figure 12. Group velocity distributions $\left(V_{P}, V_{S 1}, V_{S 2}\right)$ as well as shear wave splitting $\Delta V_{S}$ in Tambo gneiss spherical sample during the second experimental run ((a) - at $0.1 \mathrm{MPa}$ and (b) - at $100 \mathrm{MPa}$ pressure) (Fig. 2b, black lines) and different Tambo gneiss models ((c) - without pores and cracks; (d) - with 0.1 vol. $\%$ of primary cracks; (e) - with 0.1 vol. $\%$ of primary cracks and 0.6 vol.\% of secondary cracks ( $c f$. Fig. $2 \mathrm{~b}$, red lines); (f) - with 2.6 vol. $\%$ of primary cracks and 1.0 vol. $\%$ of secondary cracks). Fast $S$-wave polarization projections for different wave propagation directions are shown as red dashes on corresponding projections. Minimum and maximum velocity values, as well as A-V anisotropy coefficient are shown. Equal area projections, linear scale contours normalized to the minimum and maximum of each projection. 
Table 3. Single crystal elastic properties [GPa] and density values $\left[\mathrm{kg} \mathrm{m}^{-3}\right]$ for minerals composing the Tambo gneiss. All elastic constants are in $Z\|c, Y\| c \times a, X=Y \times Z$, assuming first setting for monoclinic muscovite and orthoclase.

\begin{tabular}{|c|c|c|c|c|}
\hline Reference & $\begin{array}{l}\text { Albite } \\
\text { (Brown et al. } \\
2006 \text { ) }\end{array}$ & $\begin{array}{l}\text { Muscovite } \\
\text { (Vaughan \& } \\
\text { Guggenheim } \\
\text { 1986) }\end{array}$ & $\begin{array}{l}\text { Orthoclase } \\
\text { (Waeselmann } \\
\text { et al. 2016) }\end{array}$ & $\begin{array}{l}\text { Quartz } \\
\text { (Heyliger et al. } \\
\text { 2003) }\end{array}$ \\
\hline$\rho$ & 2623.0 & 2844.0 & 2560.0 & 2646.6 \\
\hline $\mathrm{C}_{11}$ & 69.07 & 58.6 & 158.40 & 87.26 \\
\hline $\mathrm{C}_{12}$ & 34.65 & 25.6 & 25.00 & 6.57 \\
\hline $\mathrm{C}_{13}$ & 29.95 & 21.2 & 20.60 & 11.95 \\
\hline $\mathrm{C}_{14}$ & 4.72 & 0.0 & 0.0 & -17.18 \\
\hline $\mathrm{C}_{15}$ & -2.30 & 0.0 & 0.0 & 0.0 \\
\hline $\mathrm{C}_{16}$ & -0.86 & 1.0 & 10.60 & 0.0 \\
\hline $\mathrm{C}_{22}$ & 181.13 & 181.0 & 67.80 & 87.26 \\
\hline $\mathrm{C}_{23}$ & 6.29 & 48.8 & 40.40 & 11.95 \\
\hline $\mathrm{C}_{24}$ & -13.16 & 0.0 & 0.0 & 17.18 \\
\hline $\mathrm{C}_{25}$ & -7.53 & 0.0 & 0.0 & 0.0 \\
\hline $\mathrm{C}_{26}$ & -6.93 & -14.2 & -1.10 & 0.0 \\
\hline $\mathrm{C}_{33}$ & 180.71 & 178.4 & 181.20 & 105.80 \\
\hline $\mathrm{C}_{34}$ & 0.50 & 0.0 & 0.0 & 0.0 \\
\hline $\mathrm{C}_{35}$ & 8.00 & 0.0 & 0.0 & 0.0 \\
\hline $\mathrm{C}_{36}$ & -8.3 & 1.1 & -12.90 & 0.0 \\
\hline $\mathrm{C}_{44}$ & 25.59 & 72.0 & 33.10 & 57.15 \\
\hline $\mathrm{C}_{45}$ & -0.73 & -5.2 & -11.60 & 0.0 \\
\hline $\mathrm{C}_{46}$ & -7.61 & 0.0 & 0.0 & 0.0 \\
\hline $\mathrm{C}_{55}$ & 26.75 & 16.5 & 21.10 & 57.15 \\
\hline $\mathrm{C}_{56}$ & -0.09 & 0.0 & 0.0 & -17.18 \\
\hline $\mathrm{C}_{66}$ & 33.45 & 19.5 & 19.40 & 40.345 \\
\hline Remark & $\begin{array}{l}\text { The coordinate } \\
\text { system in (Brown } \\
\text { et al. 2006) is } Y \| b \text {, } \\
X \| a^{*}=b \times c, \\
Z=X \times Y \text {. Elastic } \\
\text { tensor here has } \\
\text { been rotated to } \\
\text { conventional } \\
\text { coordinate } \\
\text { system: } Z \| c, \\
Y \| c \times a, X=Y \times Z\end{array}$ & $\begin{array}{l}\text { The coordinate } \\
\text { system in [2] is } \\
Z \| c, Y|| b^{*}=c \times a, \\
X=Y \times Z \text {, but } \\
\text { monoclinic } \\
\text { second setting } \\
\text { with a cell angle } \\
\beta>90^{\circ} \text { is used. } \\
\text { Elastic tensor here } \\
\text { has been switched } \\
\text { to monoclinic first } \\
\text { setting (Matthies } \\
\text { \& Wenk 2009) }\end{array}$ & $\begin{array}{l}\text { Elastic properties } \\
\text { and density } \\
\text { correspond to } \\
\text { Or93Ab7 feldspar. } \\
\text { Elastic tensor here } \\
\text { has been switched } \\
\text { to monoclinic first } \\
\text { setting (Matthies } \\
\text { \& Wenk 2009) }\end{array}$ & $\begin{array}{l}\text { Right handed } \\
\text { quartz }\end{array}$ \\
\hline
\end{tabular}

single crystal elastic tensor of the mineral is given. Here we consider non-spherical grain shape for muscovite only. Based on thin sections analysis (Fig. 3) and tomography data, muscovite grains can be approximated by oblate spheroidal shape with a rather high aspect ratio between 1:1 and 1:6. But as it is evident from Fig. 3, each muscovite grain is split onto parallel 'subgrains' by series of subparallel flat cracks. Thus for the calculation of elastic properties we incorporate the muscovite into the model as these more oblate 'subgrains' with axes $\{1: 1: 0.05\}$ in the coordinate system related to the muscovite grain, considering second monoclinic setting for the muscovite with the cleavage plane (001).

The list of elastic coefficients of Tambo gneiss obtained by several modelling methods is given in Table 4 (in Voigt two-index notation). As expected, Reuss averaging provides lower $\mathrm{C}_{\mathrm{ij}}$ coefficients than the Voigt method; results of the GEO method are intermediate. It is interesting, that for the Tambo gneiss a simple geometric mean averaging provides elastic coefficients that differ from self-consistent GMS method by only about $1 \mathrm{GPa}$. There is only minor influence of muscovite grain shapes on calculated elastic properties of Tambo gneiss, as is evident from the comparison of the GMS-sphere model and the GMS-0.05 model (last two columns in Table 4). This is in agreement with observations of Nishizawa \& Yoshino (2001) and
Vasin et al. $(2013,2014)$ that the influence of grain shapes of sheet silicates on bulk elastic properties of rocks is limited.

Modelling also highlights the influence of individual minerals on bulk elastic properties of Tambo gneiss. The contribution of muscovite to the total elastic anisotropy of Tambo gneiss is the largest, due to its strong CPO and the very high single crystal anisotropy of this mineral. Preferred orientations of albite and orthoclase, though rather weak, also contribute to the increase in elastic anisotropy. Maximum shear wave splitting for all minerals is observed in the foliation plane (muscovite, orthoclase) or close to it (albite, quartz).

Based on the elastic constants of the GMS-0.05 (Table 4) model and bulk density value of $2.635 \mathrm{~g} \mathrm{~cm}^{-3}$ we calculated wave velocity distributions for Tambo gneiss without pores and cracks. First, phase wave velocities and wave polarizations have been calculated in a regular $1^{\circ} \times 1^{\circ}$ grid of polar and azimuthal angles. Using these, group (or ray) velocity vectors were recalculated. Dependencies of group velocity values on ray directions were interpolated into a regular $5^{\circ} \times 5^{\circ}$ grid, and plotted on projections (Fig. 12c). It should be noted, that minimum and maximum velocity values given in Fig. 12 correspond to the $5^{\circ} \times 5^{\circ}$ grid, and are slightly different from the absolute minimum and maximum velocities in the material. 
Table 4. Bulk elastic properties of the Tambo gneiss without pores and cracks calculated using different micromechanical models (all values are in $\mathrm{GPa}$ ).

\begin{tabular}{|c|c|c|c|c|c|}
\hline Model & Reuss & Voigt & GEO & $\begin{array}{l}\text { GMS (spherical } \\
\text { muscovite grains) }\end{array}$ & $\begin{array}{c}\text { GMS-0.05 } \\
\text { (platelet-shaped } \\
\text { muscovite grains } \\
\{1: 1: 0.05\} \text { ) }\end{array}$ \\
\hline $\mathrm{C}_{11}$ & 90.9 & 116.0 & 103.3 & 102.7 & 104.0 \\
\hline $\mathrm{C}_{12}$ & 25.0 & 26.5 & 26.3 & 25.5 & 26.3 \\
\hline $\mathrm{C}_{13}$ & 23.8 & 25.1 & 25.1 & 24.2 & 25.0 \\
\hline $\mathrm{C}_{14}$ & -0.1 & 0.0 & 0.0 & 0.0 & 0.0 \\
\hline $\mathrm{C}_{15}$ & 0.6 & 0.7 & 0.7 & 0.6 & 0.8 \\
\hline $\mathrm{C}_{16}$ & -0.6 & -0.7 & -0.7 & -0.7 & -0.7 \\
\hline $\mathrm{C}_{22}$ & 92.4 & 118.2 & 105.3 & 104.7 & 105.8 \\
\hline $\mathrm{C}_{23}$ & 23.8 & 24.6 & 24.9 & 24.0 & 24.8 \\
\hline $\mathrm{C}_{24}$ & -0.9 & -1.1 & -1.0 & -1.0 & -1.1 \\
\hline $\mathrm{C}_{25}$ & 0.0 & 0.1 & 0.0 & 0.0 & 0.1 \\
\hline $\mathrm{C}_{26}$ & -0.5 & -0.5 & -0.5 & -0.5 & -0.5 \\
\hline $\mathrm{C}_{33}$ & 82.8 & 104.1 & 92.9 & 92.6 & 91.8 \\
\hline $\mathrm{C}_{34}$ & -0.1 & -0.4 & -0.3 & -0.3 & -0.3 \\
\hline $\mathrm{C}_{35}$ & 0.0 & 0.2 & 0.1 & 0.1 & 0.1 \\
\hline $\mathrm{C}_{36}$ & 0.0 & 0.1 & 0.1 & 0.0 & 0.1 \\
\hline $\mathrm{C}_{44}$ & 30.1 & 41.3 & 35.1 & 35.4 & 34.8 \\
\hline $\mathrm{C}_{45}$ & -0.1 & -0.2 & -0.1 & -0.1 & -0.2 \\
\hline $\mathrm{C}_{46}$ & 0.2 & 0.2 & 0.2 & 0.2 & 0.3 \\
\hline $\mathrm{C}_{55}$ & 30.1 & 41.3 & 35.1 & 35.4 & 34.7 \\
\hline $\mathrm{C}_{56}$ & -0.2 & -0.3 & -0.3 & -0.3 & -0.3 \\
\hline $\mathrm{C}_{66}$ & 33.4 & 45.5 & 39.1 & 39.2 & 39.4 \\
\hline
\end{tabular}

Table 5. Bulk elastic properties of Tambo gneiss calculated from ultrasonic measurements (second run, with both $P$ and $S$ velocities) on the spherical sample, as well as elastic constants of two Tambo gneiss models including crack systems (all values are in GPa).

\begin{tabular}{lcccc}
\hline & $\begin{array}{c}\text { Model: } 0.1 \text { vol.\% of } \\
\text { measurements at } \\
\text { primary cracks and } \\
0.6 \text { vol.\% of } \\
\text { secondary cracks }\end{array}$ & $\begin{array}{c}\text { Inverted from } \\
\text { measurements at } \\
0.1 \mathrm{MPa}\end{array}$ & $\begin{array}{c}\text { Model: } 2.6 \text { vol.\% of } \\
\text { primary cracks and } \\
1.0 \text { vol.\% of } \\
\text { secondary cracks }\end{array}$ \\
\hline $\mathrm{C}_{11}$ & 99.2 & 99.8 & 42.9 & 43.8 \\
$\mathrm{C}_{12}$ & 30.3 & 23.1 & 17.0 & 5.9 \\
$\mathrm{C}_{13}$ & 27.8 & 21.9 & 15.0 & 2.9 \\
$\mathrm{C}_{14}$ & -1.4 & -0.1 & -0.5 & -0.4 \\
$\mathrm{C}_{15}$ & -1.5 & 0.9 & -1.4 & 1.6 \\
$\mathrm{C}_{16}$ & -1.7 & -0.8 & -2.8 & -2.1 \\
$\mathrm{C}_{22}$ & 93.8 & 95.6 & 26.8 & 40.3 \\
$\mathrm{C}_{23}$ & 32.3 & -1.0 & 9.7 & 2.9 \\
$\mathrm{C}_{24}$ & -0.9 & 0.1 & -0.8 & -1.9 \\
$\mathrm{C}_{25}$ & 1.0 & -0.6 & -0.6 & 0.3 \\
$\mathrm{C}_{26}$ & 0.4 & 82.7 & -2.5 & -2.0 \\
$\mathrm{C}_{33}$ & 82.2 & -0.5 & -0.1 & 13.1 \\
$\mathrm{C}_{34}$ & -0.7 & 0.3 & -0.5 & -1.0 \\
$\mathrm{C}_{35}$ & -0.1 & 0.0 & -1.9 & 0.8 \\
$\mathrm{C}_{36}$ & 3.6 & 32.1 & 3.6 & -0.2 \\
$\mathrm{C}_{44}$ & 26.4 & -0.2 & 0.2 & 9.7 \\
$\mathrm{C}_{45}$ & -1.0 & 0.3 & 0.2 & -0.5 \\
$\mathrm{C}_{46}$ & 0.5 & -0.4 & 4.3 & 0.7 \\
$\mathrm{C}_{55}$ & 28.6 & 37.2 & -0.4 & 10.1 \\
$\mathrm{C}_{56}$ & 0.6 & & 8.5 & -0.9 \\
$\mathrm{C}_{66}$ & 32.6 & & & 18.1 \\
\hline
\end{tabular}

$P$-wave velocities distributions based on self-consistent model GMS-0.05 considering platelet shaped muscovite grains (Fig. 12c) compare well to measurements at $400 \mathrm{MPa}$ pressure (Fig. 11). The minimum and maximum $V_{P}$ values for the model (Fig. 12c) are comparable with the ultrasonic measurements at pressures of $400 \mathrm{MPa}$ presented in Fig. 10. Their positions also match. The model has a slightly lower A- $V_{P}$ coefficient (7.0 per cent compared with 9.6 per cent and 8.4 per cent measured on cube and on sphere correspondingly). The measured $V_{P}$ distribution (Fig. 10) is close to axisymmetric around $Z$ with maximum velocity directions in the foliation $(X Y)$, while the model distribution has two subsidiary maxima and two minima in the foliation plane, resulting in the orthorhombic 
symmetry of the model. But quantitative differences between measured and modelled $P$-wave velocities are less than $0.1 \mathrm{~km} \mathrm{~s}^{-1}$ that is comparable with experimental errors. Also, a small amount of oriented microfractures could be still present in the material at $400 \mathrm{MPa}$ pressure, affecting the overall symmetry of elastic properties.

For $S$ waves at a pressure of $400 \mathrm{MPa}$ there are only measurements on the cube sample in structural directions $X, Y, Z$. According to these measurements, velocities of fast $S$ waves at $400 \mathrm{MPa}$ pressure range from 3.50 to $3.73 \mathrm{~km} \mathrm{~s}^{-1}$, and velocities of slow $S$ waves are $\approx$ $3.48-3.59 \mathrm{~km} \mathrm{~s}^{-1}$. These values differ from the model by less than $0.14 \mathrm{~km} \mathrm{~s}^{-1}$ (less than 4 per cent). We conclude that model elastic properties based on 'effective medium' self-consistent approach without assuming pores or fractures provide a good description at the highest pressure $(400 \mathrm{MPa})$.

The description of the elastic properties of Tambo gneiss at lower pressure (where elastic waves propagate slower and the gneiss is more anisotropic) requires the introduction of cracks into the model. Thin sections analysis revealed presence of microcracks within mica grains (Fig. 3) that could be divided on two systems based on their orientation. One system is parallel to the platy grains, and the other one is normal to subnormal to them (red arrows in Figs $3 a$ and b). This it is in line with observations of Schoenberg \& Sayers (1995) and their model of elastic properties of fractured rocks dividing fractures into different sets, based on orientations.

The consideration of microcracks into the GMS-based model requires the knowledge of their SPO. In our previous studies on gneiss (Wenk et al. 2012) and porous shales (Vasin et al. 2013; Kanitpanyacharoen et al. 2015) we assumed that the only nonspherical pores or fractures are oblate spheroids with aspect ratio of 0.01 and are subparallel to the grains of sheet silicates. Similar preferred orientation distributions of flat pores have been observed in composite ceramic materials with flat grains (Onel et al. 2013), using the statistical analysis of X-ray computed tomography data.

For Tambo gneiss we approximated intracrystalline fractures parallel to muscovite grains (primary system of cracks) by ellipsoids with axes $\{1: 1: 0.01\}$ (in the coordinate system related to the grains of muscovite considering the second monoclinic setting) and attributed to them the muscovite SPO with a low but non-zero random component (Table 2). Thus, the introduction of this crack system would lead to a visible decrease of Tambo gneiss stiffness and velocities of elastic waves propagating in all directions. With the increase of the volume fraction of these cracks the largest decrease of model Tambo gneiss stiffness would be normal to foliation $(Z)$ while within the foliation plane $(X Y)$ the decrease would be less pronounced. The elastic anisotropy of Tambo gneiss will also increase with the increase of the volume of primary cracks. Such a behaviour is in line with the observed cube sample deformations (Fig. 8) and $P$-wave velocity curves (Fig. 9).

We calculated several models of Tambo gneiss containing different amount of primary cracks. As an example, the variant containing 0.1 vol.\% of primary cracks is shown in Fig. 12(d). Indeed, elastic wave velocities in this model are smaller than in model without cracks (Fig. 12c), and the elastic anisotropy increased. The model with 0.1 vol. $\%$ of primary cracks is characterized by minimum and maximum $V_{P}$ values that are very close to those measured on a spherical sample at $100 \mathrm{MPa}$ (Figs 11 and 12b). $V_{P}$ and $V_{S}$ distributions also are similar, except for one notable difference: the maximum $V_{P}$ locations (both modelled and measured) are in the foliation plane but for the measured velocity distribution (Fig. 12b) the maximum is inclined by an angle of $\approx 25^{\circ}$ to the lineation direction $X$, and for the model (Fig. 12d), the angle is $\approx 60^{\circ}$. The same difference is observed for the $V_{S 2}$ distribution, as well as for $S$-wave polarizations.

This rotation is too large to be attributed to the misorientation of the spherical sample during velocity and neutron diffraction experiments and we attribute it to features of the sample microstructure not considered in a model featuring only one system of fractures. From the modelling point of view, it is necessary to introduce new features into the model, decreasing model elastic wave velocities propagating closer to the $\mathrm{Y}$ direction than to $\mathrm{X}$ direction, rather than arbitrarily 'rotating' model velocity distributions. This situation is similar to the modelling of the Outokumpu gneiss properties made by Schijns et al. (2012), where the resulting elastic wave velocities distributions were tilted compared to the initial crack-free state due to the presence of several systems of cracks. It is evident that a second crack system should be considered to correctly model elastic properties at $100 \mathrm{MPa}$ pressure.

Even though the presence of microcracks roughly normal to the foliation plane $(X Y)$ is confirmed by microscopy (Fig. 3, red arrows), their orientation distribution is less constrained. We arbitrarily select the SPO for secondary cracks to be consistent with the observed elastic properties (Figs 12a and b). The simplest assumption is that they are subnormal to $Y$. Since these cracks only appear within mica grains, their axes ratios should be consistent with the shape of muscovite grains. Thus we define the secondary set of cracks as ellipsoids with $\{1: 0.01: 0.05\}$ axes fixed in the structural coordinate frame $\{X, Y, Z\}$ of the Tambo gneiss. Velocity distributions for a model with 0.1 vol. $\%$ of primary cracks parallel to mica grains and 0.6 vol.\% of secondary cracks are plotted in Fig. 12(e). Positions of minimum and maximum on model velocity distributions became almost identical to measured velocity distributions at $100 \mathrm{MPa}$ (Fig. 12b). Absolute $P$-wave velocity values also are very close, while model $S$-wave velocities are slightly larger in the model by $0.2-0.3 \mathrm{~km} \mathrm{~s}^{-1}$. Fast $S$-wave $\left(\mathrm{S}_{1}\right)$ polarizations in different propagation directions for this model (Fig. 12e, see also Fig. 2b, red lines) can be compared with results where the elastic tensor was inverted from measurements at $100 \mathrm{MPa}$ (Fig. 12b, see also Fig. 2b, black lines). For many directions there is a good coincidence but there are some deviations too. We also note that $S_{1}$ polarizations in the model do not coincide with actual measurements (Fig. 2a).

For porous shales Vasin et al. (2013) and Kanitpanyacharoen et al. (2015) have shown that elastic properties at lower confining pressures could be obtained from a 'high pressure' model by considering additional amount of thin flat pores subparallel to platelet-shaped grains of sheet silicates. For Tambo gneiss we had to introduce two systems of low aspect ratio cracks already at $100 \mathrm{MPa}$ pressure. Thus, it would be reasonable to increase the amount of both primary and secondary cracks in the 'high pressure' model (Fig. 12e) in order to match elastic wave velocities measured at a pressure of $0.1 \mathrm{MPa}$.

Fig. 12(f) shows a model with 2.6 vol.\% of primary cracks and 1.0 vol.\% of secondary cracks. We note that $P$-wave distributions and shear wave splitting $\Delta S$ are very close to those observed at a pressure of $0.1 \mathrm{MPa}$ (Fig. 11). $V_{S 1}$ distributions also possess the same outline (are close to transversely isotropic). But in this case model $V_{S}$ values exceed the measured ones by a significant margin $\left(\sim 0.7 \mathrm{~km} \mathrm{~s}^{-1}\right)$. Interestingly, fast $S$-wave polarizations for this model are comparable with those recalculated from the inverted elastic tensor at $0.1 \mathrm{MPa}$ for most wave propagation directions. The largest difference between modelled and inverted $V_{S 1}$ polarizations is observed for propagation directions close to the foliation plane. 
We conclude that the agreement between self-consistent models of Tambo gneiss and measured elastic wave velocities is good at high pressures $(>100 \mathrm{MPa})$, but there are some differences at $0.1 \mathrm{MPa}$.

\section{DISCUSSION}

\subsection{Comparison of two ultrasonic experiments}

We used two different ultrasonic methods to determine elastic wave velocities and elastic anisotropy in a metamorphic gneiss from the Tambo Nappe. Measurements have been performed in a multi-anvil apparatus with a cube sample and in a special pressure device with a spherical sample, using oil as a pressure medium to impose hydrostatic pressure.

Both methods provide similar dependencies of elastic wave velocities on pressure (Figs 9 and 10), demonstrating a rapid increase of velocities (and corresponding decrease of anisotropy coefficients) at lower pressures (below $100 \mathrm{MPa}$ ). At higher pressures (100-400 MPa) elastic wave velocities increase only slightly, showing quasi-linear dependence on pressure. This behaviour is common for gneisses (e.g. Ivankina et al. 2005; Kern et al. 2009, 2015).

Experiments on the cube and on the sphere yield $P$-wave velocities (Fig. 9) that are very close. In the experiment on the sphere $V_{P}$ values in $X$ and $Y$ directions are practically equal (difference less than $0.1 \mathrm{~km} \mathrm{~s}^{-1}$ ) at pressures higher than $50 \mathrm{MPa}$, while in the experiment on cube a distinct difference remains $\left(0.24 \mathrm{~km} \mathrm{~s}^{-1}\right.$ at $100 \mathrm{MPa}$ pressure and $0.17 \mathrm{~km} \mathrm{~s}^{-1}$ at $406 \mathrm{MPa}$ ). The experiment on the cube also shows a slightly slower $P$-wave propagation in the $Z$ direction and, consequently, a higher anisotropy coefficient compared with the sphere. At $400 \mathrm{MPa}$ pressure anisotropies are 9.6 per cent for the cube and 8.4 per cent for the sphere. These differences could be attributed to minor compositional variations between the two samples, or small misorientations between the positioning of samples in ultrasonic measuring devices. The lineation direction is not well pronounced in the sample block and may deviate from the regional lineation established by structural geology (Wenk 1973). As is evident from sphere measurements (Figs 12a and $\mathrm{b}$ ), the maximum $V_{P}$ values in Tambo gneiss does not coincide with $X$, assumed to be the lineation. Thus, a misorientation around the foliation normal by several degrees can lead to a change in $\mathrm{V}_{P}[\mathrm{Y}] / \mathrm{V}_{P}[\mathrm{X}]$ and in anisotropy coefficient that is derived based on these values. As we see in Fig. 10, $V_{S}$ values obtained in $\mathrm{X}, \mathrm{Y}, \mathrm{Z}$ directions on the cube and on the sphere at a pressure of $100 \mathrm{MPa}$ are equal within experimental error margins. This is a major improvement compared to earlier work of Kern et al. (2015) who detected significant differences between shear wave velocities measured on cubic and spherical samples.

We note that in anisotropic materials it is important to distinguish between phase and group velocities. Depending on the geometry of the ultrasonic experiment and size of sensors either phase or group velocities of elastic waves are measured. To measure group velocities, the ratio of wave propagation distance to size of the sensor should be more than 20 (Dellinger \& Vernik 1994). Consequently, phase velocities were measured on the cube (with relatively large area sensors) and group velocities on the sphere (with quasi-point contact sensors over $50 \mathrm{~mm}$ large sample). But at $100 \mathrm{MPa}$ pressure the anisotropy of Tambo gneiss is less than 10 per cent and consequently phase and group wave velocity values should be very close, and ray directions may not deviate significantly from wave front normals. For such conditions, it is expected for both ultrasonic methods to provide similar results.

Both applied methods have specific advantages. Due to large area contact sensors, $S$-wave measurements in multi-anvil apparatus can be performed without any difficulties at a wide pressure range. The high pressure ultrasonic measurements setup on spherical samples uses high viscosity grease to provide the $S$-wave propagation through the quasi-point contact on the sample surface. Possible limitation to the quasi-point contact scheme is the low signal intensity that makes it more difficult to correctly determine the first arrival of the elastic wave. $S$ waves are more affected by this problem, and especially at low pressures where rocks may still have considerable porosity that causes signal damping. A similar effect was explored by Mah \& Schmitt (2001a,b) by using $S_{v}$ modes at oblique propagation angles from the $\mathrm{P}$ point source, but their solution could not be applied for the ultrasonic measurements on spheres where both the transmitter and the receiver are fixed on the sample's diameter.

On the other hand, measurements in multiple directions in the spherical sample provide a complete picture of the $P$ - and $S$-wave velocity distributions. During measurements in only three orthogonal directions on a cube sample, it was impossible to identify deviations from assumed transversely isotropic symmetry of wave velocity distributions. Additionally, obtaining abundant information on wave velocities permits the inversion of the complete stiffness tensor of an anisotropic rock without having to make assumptions about sample symmetry.

\subsection{Microstructural characterization}

To understand the sources of elastic anisotropy of Tambo gneiss we have applied several analytical methods to study its microstructure. Neutron diffraction helped to assess the mineral composition and provided quantitative information on CPOs of minerals. Muscovite has the strongest texture, while preferred orientations of feldspars and quartz are less pronounced. This is in agreement with other studies of gneisses, where sheet silicates tend to demonstrate strong fibre-like textures with the symmetry axis close to the foliation normal (e.g. Kern et al. 2009; Wenk et al. 2012) and have the biggest impact on the overall elastic anisotropy. Quartz and feldspars influence bulk elastic anisotropy to a much lesser extent. We note that similar quartz textures in gneiss have been attributed to low temperature deformation under flattening strain by combination of basal and rhombohedral slip (Little et al. 2013). The maximum near the $Z$ direction on the $\{10 \overline{1} 1\}$ pole figure of quartz, and corresponding minimum on the $\{01 \overline{1} 1\}$ pole figure (Fig. 5a) could be caused by the development of Dauphiné twinning (e.g. Pehl \& Wenk 2005) due to compressive stress in the $Z$ direction. CPO patterns in Tambo gneiss confirm observations that in gneisses quartz develops minimal preferred orientation compared to muscovite-bearing quartzites (e.g. Wenk et al. 2010a), presumably due to strain heterogeneities in polyphase rocks with strong and weak phases (e.g. Tullis \& Wenk 1994).

Optical microscopy and computed tomography confirmed and quantified the flat shape of the muscovite platelets and their SPO more or less within the foliation plane. We note that in our case optical microscopy made on thin sections had a resolution superior to that of neutron and X-ray tomography. Microscopy revealed intergranular cracks in mica (Fig. 3) that were below the resolution of tomography methods. These cracks could be attributed to two types. Primary cracks, parallel to muscovite grains, are generated by the 
Table 6. Some characteristics of gneisses: volume fraction of sheet silicates, minimum and maximum pole densities on the pole figure of the cleavage plane (001), anisotropy coefficient A- $V_{P}$ and maximum shear wave splitting (at pressures of 25 and $400 \mathrm{MPa}$ ).

\begin{tabular}{|c|c|c|c|c|c|c|c|c|}
\hline $\begin{array}{l}\text { Gneiss } \\
\text { Reference }\end{array}$ & $\begin{array}{c}\text { Tambo gneiss } \\
\text { This work }\end{array}$ & $\begin{array}{c}\text { Outokumpu } \\
676 \\
\text { Kern et al. } 2009\end{array}$ & $\begin{array}{l}\text { Outokumpu } \\
\quad 818 \\
\text { Kern } \text { et al. } \\
\text { 2009; Wenk } \\
\text { et al. } 2012\end{array}$ & $\begin{array}{c}\text { Kola } 36058 \\
\text { Kern et al. } 2001\end{array}$ & $\begin{array}{c}\text { Kola 38098S } \\
\text { Kern et al. } 2001\end{array}$ & $\begin{array}{c}\text { Kola PP358 } \\
\text { Kern et al. } 2001\end{array}$ & $\begin{array}{c}\text { Kola PP363 } \\
\text { Kern et al. } 2001\end{array}$ & $\begin{array}{c}\text { Verzasca gneiss } \\
\text { Wang et al. } \\
1975\end{array}$ \\
\hline $\begin{array}{l}\text { vol. } \% \text { of sheet } \\
\text { silicate }\end{array}$ & 17.5 & 19.8 & 22.6 & 31 & 30 & 23 & 23 & 30 \\
\hline Min. (001) & 0.08 & 0.30 & 0.03 & & & & & \\
\hline Max. (001) & 10.04 & 9.79 & 23.2 & & & & & \\
\hline $\begin{array}{l}\text { A- } V_{P}, \text { per cent } \\
(25 \mathrm{MPa})\end{array}$ & 27.07 & 19.28 & 26.27 & 44.33 & 33.41 & 19.74 & 17.17 & $\approx 20$ \\
\hline $\begin{array}{l}\text { A- } V_{P}, \text { per cent } \\
(400 \mathrm{MPa})\end{array}$ & $8.4-9.6$ & 13.82 & 13.86 & 23.86 & 15.12 & 9.49 & 12.41 & $\approx 10^{a}$ \\
\hline $\begin{array}{l}\Delta V_{\text {Smax }}, \mathrm{km} \mathrm{s}^{-1} \\
(25 \mathrm{MPa})\end{array}$ & 0.53 & 0.52 & 0.36 & 0.88 & 0.42 & 0.20 & 0.57 & $\approx 0.5$ \\
\hline $\begin{array}{l}\Delta V_{\text {Smax }}, \mathrm{km} \mathrm{s}^{-1} \\
(400 \mathrm{MPa})\end{array}$ & 0.42 & 0.55 & 0.3 & 1.04 & 0.58 & 0.18 & 0.52 & $\approx 0.5^{a}$ \\
\hline
\end{tabular}

${ }^{a}$ At a pressure of $200 \mathrm{MPa}$.

cleavage of mica crystals. Secondary cracks, normal to muscovite grains, could be formed by the extensional strain in the foliation plane. In the Tambo gneiss sample some of the microcracks were likely produced during sample extraction in the quarry, where explosive techniques are employed.

Well established microscopy methods also allow differentiation between such minerals as quartz and feldspars. Both neutron and X-ray tomography had insufficient contrast. But the advantage of those tomography methods is that they can study the same sample that is used for the ultrasonic measurements and diffraction studies.

For the spherical ( $5 \mathrm{~cm}$ in diameter) Tambo gneiss sample neutron computed tomography revealed layers with relatively high mica content (light bands in Fig. 6), as well as layers enriched in quartz and feldspars (dark bands in Fig. 6). X-ray computed tomography was performed on a smaller sample, and it demonstrated at higher resolution a similar layering pattern of mica (white flattened particles in Fig. 7b). The higher resolution of the X-ray tomography also helped to reveal that mica platelets are often isolated from each other by quartz-feldspar matrix that is supported by optical microscopy (Fig. 3). Some subsidiary pyrite inclusions as well as very low amounts of spherical pores were identified by X-ray tomography.

Microstructural information was used to compute bulk stiffness coefficients of Tambo gneiss that could now be directly compared with those inverted from ultrasonic measurements on the sphere.

\subsection{Comparison of stiffness coefficients from experimental inversion and microstructural model}

Individual elastic stiffness coefficients $C_{i j}$ inverted from ultrasonic measurements at pressures of 0.1 and $100 \mathrm{MPa}$ are summarized in Table 5 and compared with stiffness coefficients of corresponding elastic properties models. Both inverted elastic tensors are derived from measurements made during run 2 where $S$-wave velocities were available that allows better determination of stiffness coefficients with $(i, j)=4,5,6$ (Svitek et al. 2014).

Off-diagonal parameters (except those corresponding to the Poisson expansion: $\mathrm{C}_{12}, \mathrm{C}_{13}, \mathrm{C}_{23}$ ) of elastic tensors in Table 5 are very close to zero. This fact suggests that tensors are oriented close to the structural symmetry that is roughly orthorhombic. Stiffness coeffi- cients $\mathrm{C}_{11}, \mathrm{C}_{22}$ and $\mathrm{C}_{33}$ inverted at $100 \mathrm{MPa}$ are practically equal to coefficients of the corresponding model. The comparison between other diagonal coefficients, governing shear wave propagation$\mathrm{C}_{44}, \mathrm{C}_{55}$ and $\mathrm{C}_{66}$ - is not that good; model coefficients are higher by 14-22 per cent, thus the model suggests a bit faster propagation of $S$ waves than detected in the experiment. Off-diagonal coefficients $\mathrm{C}_{12}, \mathrm{C}_{13}$ and $\mathrm{C}_{23}$ are, in turn lower by $21-35$ per cent than inverted from measured velocities. This is comparable to differences in $\mathrm{C}_{13}$ coefficient between self-consistent models of elastic properties and ultrasonic measurements in our previous studies of transversely isotropic shales (Vasin et al. 2013; Kanitpanyacharoen et al. 2015).

At $0.1 \mathrm{MPa}$ the situation remains almost the same. Off-diagonal coefficients that were close to zero at $100 \mathrm{MPa}$ retain their low values. Stiffness coefficients $C_{11}$ and $C_{33}$ inverted from wave velocities compare well to corresponding coefficients of the model. Again the model provides higher $\mathrm{C}_{44}, \mathrm{C}_{55}$ and $\mathrm{C}_{66}$ coefficients (and faster $S$ waves propagation), and much lower off-diagonal coefficients $\mathrm{C}_{12}$, $\mathrm{C}_{13}$ and $\mathrm{C}_{23}$. Also at $0.1 \mathrm{MPa}$ pressure inverted and modelled $\mathrm{C}_{22}$ coefficients differ by $13.5 \mathrm{GPa}(\approx 50$ per cent).

It is interesting to note that two different models of the Outokumpu borehole gneiss at $200 \mathrm{MPa}$ pressure, one using the GMS averaging (Wenk et al. 2012), and the other one (Schijns et al. 2012) using the approach of Schoenberg \& Sayers (1995) of rotationally invariant fracture sets provided elastic constant very similar to our model. In both models of the Outokumpu gneiss elastic coefficients $\mathrm{C}_{12}, \mathrm{C}_{13}$ and $\mathrm{C}_{23}$ are around 20-24 GPa, while coefficients $\mathrm{C}_{44}, \mathrm{C}_{55}$ and $\mathrm{C}_{66}$ are above $30 \mathrm{GPa}$. This is also true for the GMS model of the Tambo gneiss, but not for the elastic tensor inverted from the measured elastic wave velocities.

\subsection{Peculiarities and limitations of the model of elastic properties}

What are possible errors in the model of elastic properties that could affect resulting elastic coefficients and cause poor comparison with the experiment?

Mineral volume fractions and preferred orientations are well constrained by the neutron diffraction experiment performed on the same spherical sample. Elastic properties of minerals composing Tambo gneiss are well known. 
We neglected the change of elastic constants with pressure. The work of Calderon et al. (2007) suggests that for quartz the stiffness coefficients between 0.1 and $400 \mathrm{MPa}$ increase almost linearly by $\approx 1-2 \mathrm{GPa}$. Similar changes may be expected in feldspars. Muscovite may have a higher increase of elastic coefficients with pressure. But reasonably, related increases in elastic wave velocities in Tambogneiss are not expected to exceed $0.1 \mathrm{~km} \mathrm{~s}^{-1}$ even at $400 \mathrm{MPa}$ pressure. As the modeling has shown, errors in modelled bulk stiffness coefficients introduced by not considering the actual distribution of muscovite grains on shape are of $\approx 1 \mathrm{GPa}$ order, and corresponding errors in recalculated elastic wave velocities are expected to be about $20-30 \mathrm{~m} \mathrm{~s}^{-1}$. We expect errors of the same order related to other minor effects, such as presence of small amounts of pyrite, very low volume of spherical porosity, etc. Naturally, all these effects would not change the symmetry of elastic properties of Tambo gneiss model, nor make a visible impact on its anisotropy.

The self-consistent GMS algorithm was used to gather all the microstructural information into bulk elastic constants. It is valid in 'long-wave' approximation (e.g. Berryman 1980), that is it should correctly describe acoustic wave velocities in the model medium when their wavelengths are significantly longer than the size of heterogeneities in it. If the wavelengths are shorter than the size of heterogeneities then elements of ray tracing methods should be used to describe the propagation of elastic wave velocities in the medium (e.g. Marion et al. 1994; Gelinsky \& Shapiro 1997; Costa e Silva \& Stovas 2009). Model calculations find that within the ray theory approach (high frequencies and short wavelengths) elastic wave velocities should be higher than those inferred from effective medium theories corresponding to low frequency waves (and long wavelengths) (e.g. Marion et al. 1994; Mukerji et al. 1995; Ivanov \& Stovas 2016). Tomography and optical microscopy experiments on Tambo gneiss revealed the presence of layers relatively enriched in muscovite. The thickness of these layers is generally $\approx 0.5 \mathrm{~mm}$ that is several times below wavelengths of ultrasonic waves that we have used. The 'threshold' ratio of wavelength to the scale of heterogeneities of the material (meaning not only grains of different minerals composing polyphase rock, but also grains with different orientations), over which the application of the effective medium theory is valid, clearly depends on the acoustic impedance contrasts and proportions of materials (e.g. Liu \& Schmitt 2006). It is difficult to determine this value for a general 3-D multiphase anisotropic bulk material.

Estimations made by Marion et al. (1994) suggest that in the periodically layered plastic-steel system (difference in $P$-wave velocities is $\approx 2.2$ times) elastic wavelengths should be about 10 times larger than the scale of heterogeneities to reproduce measured elastic waves velocities with the 'long-wave' effective medium theory. Similar material was studied by Liu \& Schmitt (2006), and they found that even if this difference is $30-50$ times then it still may not be enough for the effective medium theory to be correct. On the other hand, for the transversely isotropic medium composed of layers with a velocity difference of only a factor of $1.414(\sqrt{2})$, Helbig (1984) demonstrated that wavelengths three times larger than the periodicity are sufficient for the 'long-wave' approximation applicability to describe the propagation of shear waves.

Calculations by Mukerji et al. (1995) for a medium with a low difference between elastic properties of composing materials (only 4 per cent fluctuation of the velocity) have shown that already for the wavelengths 1-3 times the size of heterogeneities, $P$-wave velocities are very close to those derived from the Reuss model (the lowest estimation of the effective medium-based velocity). Also for this case $P$-wave velocities based on the Reuss model are lower than those predicted by the 3-D ray theory by 5 per cent. The Tambo gneiss is composed by feldspars, quartz and mica, and the contrast in $P$-wave velocities between these minerals is rather low. It means that the results of ultrasonic experiments using elastic wavelengths several times longer than the size of heterogeneities in Tambo gneiss could be described within the effective medium approach. Additionally, a very good agreement between the selfconsistent model without cracks and ultrasonic measurements at $400 \mathrm{MPa}$ pressure is achieved. If the ray theory was applicable to model elastic wave propagation in Tambo gneiss, experimental wave velocities would have exceeded the velocities based on a self-consisted model by several hundreds $\mathrm{m} \mathrm{s}^{-1}$. This confirms the validity of the self-consistent-based 'effective medium' approach that we took. For the same reason we made no attempts to utilize different models describing elastic properties of the layered medium (e.g. Backus 1962; Berryman et al. 1999).

GMS describes elastic properties of 'ideally disordered' polycrystals (Matthies 2010), without any correlations in the positions and orientations of neighbouring elements of the polycrystal. In the Tambo gneiss case, we approximated mica sub-grains by oblate spheroids with aspect ratio 0.05. Within real mica grains (Fig. 3) these subgrains are stacked and separated by thin cracks that we denoted as 'primary'. Consequently, there is some degree of ordering and correlation within the rock that affects elastic properties that cannot be accounted for within the GMS formalism. The 'muscovite sub-grains + associated crack' stacks (compared to uncorrelated muscovite grains and cracks) would demonstrate a more 'Reuss-like' behaviour normal to the stacking (realizing the 'equal stress' concept) becoming less stiff in this direction, but they would be more stiff in the stacking plane because in this direction they would be subjected to the same strain and act more 'Voigt-like'. And since the SPO for these stacks should be considered, they would affect all bulk elastic constants of Tambo gneiss in an irregular manner: some of them would increase compared to the case of uncorrelated mica grains and cracks, while others may decrease. The situation is even more complicated for Tambo gneiss where secondary cracks within muscovite grains should be considered. The effect of these organized 'muscovite sub-grains + associated crack' stacks would be less pronounced at $100 \mathrm{MPa}$ where most of cracks are presumably closed, but at a pressure of $0.1 \mathrm{MPa}$ it may be important.

The biggest simplification included in the models of elastic properties of Tambo gneiss at lower pressures is the consideration of only two types of cracks with fixed orientation distributions and aspect ratios, and the attempt to relate the low pressure model to the high pressure model simply by increasing the volume fractions of both types of cracks. At low pressures the situation is obviously more complex and we expect a distribution of cracks and shapes. Experimental studies suggest that such distributions can cover a wide range of aspect ratios, and cracks with aspect ratios $5 \times 10^{-5}$ or even smaller may exist in rocks (e.g. Hadley 1976). For isotropic rocks it was proposed to approximate the distribution of cracks (or pores) on shape in terms of stiff and compliant porosities (Shapiro 2003; Han 2016) where compliant pores are believed to have much lower aspect ratios than stiff ones and consequently, they close much faster as the pressure increases. Stiff pores could remain open at very high pressures, in agreement with Christensen (1974) who has shown that small amounts of high aspect ratio cracks may be preserved in rocks, even at pressures as high as $1 \mathrm{GPa}$. Ruiz \& Azizov (2011) demonstrated, that the dependence of elastic wave velocities on depth (and on pressure) could be described with the same quality by 
considering a single set of pores with a depth-dependent aspect ratio. When anisotropic materials are considered, it is natural to expect that cracks with different aspect ratios may have different orientation distributions, and these orientation distributions do change with pressure as cracks close within the anisotropic crystalline matrix. Additionally, the difference between $P$-wave velocities measured on the spherical sample at $0.1 \mathrm{MPa}$ pressure during first and second experimental runs suggests that some of the cracks are not reopened after the pressure cycle up to $400 \mathrm{MPa}$ and back. Microscopic origins of different behaviour of fractures and pores at different pressures, mechanisms of closure (including the irreversible closure) of fractures and the dependence on shape, orientation, and other factors, such as local environment may have significant impacts.

\subsection{Elastic anisotropy in gneiss}

How typical is the observed elastic anisotropy of Tambo gneiss and its dependence on pressure? Similar to other studies of elastic wave velocity propagation in gneisses, the Tambo gneiss is characterized by higher $P$-wave velocities in the foliation plane and minimum velocity normal to foliation. The same is true for the shear wave splitting. This can be directly linked to CPO of sheet silicates.

Compared to biotite gneisses from the Outokumpu borehole (Kern et al. 2009) Tambo gneiss has a lower sheet silicate content (Table 6). Muscovite in Tambo gneiss also has a significantly weaker preferred orientation [10 m.r.d. maximum (001) pole figure density] than biotite in Outokumpu gneiss 818 ( $\sim 23$ m.r.d.). Consequently, at high pressure Outokumpu gneiss is more anisotropic ( $\sim 14$ per cent) than Tambo gneiss ( $\sim 9$ per cent). Elastic properties of the Outokumpu gneiss 818 were modelled by two different methods (Schijns et al. 2012; Wenk et al. 2012), and they have shown that elastic anisotropy of this gneiss, even at increased pressure of $200 \mathrm{MPa}$, is affected by the presence of cracks.

Gneisses, collected from greater depths of the Kola boreholegneiss $36058(9571 \mathrm{~m})$ and 38098S $(10232 \mathrm{~m})$ - have relatively high biotite content (Kern et al. 2001, see also Ivankina et al. 2005) and are highly anisotropic, even at $400 \mathrm{MPa}$ pressure, but there is no information about preferred orientation of biotite. Interestingly, shear wave splitting in the foliation plane decreases for both Kola gneisses 36058 and $38098 \mathrm{~S}$ with the pressure decrease. It possibly indicates the opening of cracks oriented parallel to the foliation.

Another Alpine gneiss (Wang et al. 1975) - a higher metamorphic biotite gneiss from a Pennine nappe (Verzasca gneiss) - is characterized by $P$ - and $S$-wave velocities that are comparable to wave velocities in Tambo gneiss. The anisotropy coefficient $\mathrm{A}-\mathrm{V}_{P}$ of Verzasca gneiss was estimated as $\approx 10$ per cent at $200 \mathrm{MPa}$ and about 50 per cent at $0.1 \mathrm{MPa}$ (Table 6), very similar to Tambo gneiss. The most significant difference between Verzasca gneiss and Tambo gneiss is that at $0.1 \mathrm{MPa}$ in Verzasca gneiss measured $S$-wave velocities range is $2-3 \mathrm{~km} \mathrm{~s}^{-1}$ while for Tambo gneiss from 1.1 to $1.8 \mathrm{~km} \mathrm{~s}^{-1}$.

The data on elastic anisotropy of gneiss add important information for the interpretation of seismic tomography data of the continental crust (e.g. Lippitsch et al. 2003). An early survey described significant seismic anisotropy in a variety of Alpine metamorphic rocks (Johnson \& Wenk 1974) but those measurements were done at ambient conditions and are greatly influenced by microfractures. There are relatively few studies on seismic anisotropy of Alpine gneiss, schists, marbles, amphibolites and serpentinites (e.g.
Siegesmund et al. 1989, 1991; Siegesmund \& Kern 1990; Siegesmund \& Vollbrecht 1991; Burlini \& Fountain 1993; Kern et al. 1997; Ullemeyer et al. 2006; Jung 2011; Ji et al. 2013). With this contribution we may encourage more systematic studies to determine elastic properties of metamorphic rocks, either with advanced ultrasonic experiments or quantitative models based on microstructures. As we have shown, both produce very similar results.

\subsection{Comparison with shales}

There are many sheet silicate-rich rocks in the Earth's crust and these minerals with a sheet-like morphology are largely responsible for seismic anisotropy. The strongest preferred orientation has been observed in slates with an alignment of (001) lattice planes exceeding 50 m.r.d. (e.g. Oertel 1983; Haerinck et al. 2015). They are followed by gneisses and schists as described in the previous section (Table 6, see also Cholach \& Schmitt 2006; Wenk et al. 2010b). But by far most important are shales because of their significance in the context of hydrocarbon reservoirs. Both for seismic exploration and hydrocarbon extraction anisotropy plays a critical role and has been studied in great detail. The alignment of platelets of illite-smectite, chlorite and kaolinite ranges from 4-10 m.r.d. (e.g. Wenk et al. 2008; Kanitpanyacharoen et al. 2011, 2012, 2015; Vasin et al. 2013), the sheet silicate content in shales is often high (30-70 vol.\%) and, in addition to mineral alignment, platy porosity and layers of kerogen are major contributions to anisotropy (5-50 vol.\%). For shales the first quantitative models linking microstructures to anisotropy of elastic properties were developed (e.g. Hornby et al. 1994; Sayers 1994; Hornby 1998) and it was for shales that we first applied the GMS averaging scheme, combining CPO and porosity (Vasin et al. 2013). Some of the advances achieved in this study of gneiss, among them an improvement of the GMS code, will likely have an impact for future exploration of shale anisotropy.

\section{CONCLUSIONS}

Seismic anisotropy of Tambo gneiss from Central Alps has been assessed with two different ultrasonic methods and microstructurebased self-consistent modelling. Stiffness coefficients for Tambo gneiss were obtained without making any assumptions about sample symmetry by inverting ultrasonic wave velocities data at pressures of 0.1 and $100 \mathrm{MPa}$, and from the self-consistent averaging that relied on measured mineral composition, textures and microstructures. $P$ - and $S$-wave velocities measured by both ultrasonic methods in three structural directions - normal to foliation, in lineation, and normal to lineation in foliation-agree very well. The deviations of the symmetry of elastic properties of Tambo gneiss from transversely isotropic could only be recorded with the experiment on the sphere, though this method currently has pressure limitations for $S$-wave velocities measurements. The limited pressure range should be expanded to record intrinsic anisotropy of rocks in Earth's interior. Also, in the future it may become possible to measure $\mathrm{S}$ velocities in arbitrary directions on the sphere to properly account for polarization. The microstructure-based modelling of the elastic properties of Tambo gneiss reproduced results of ultrasonic measurements at increased pressures. A comparison of symmetries of measured and modelled velocity distributions lead to the conclusion that at a pressure of $100 \mathrm{MPa}$ two systems of cracks should be present in the model to match measured velocity distributions. It is evidence that systems of low aspect ratio cracks or pores could 
still be present in metamorphic rocks in the Earth's crust at depths corresponding to $100 \mathrm{MPa}$ pressure $(\sim 3-4 \mathrm{~km})$.

\section{ACKNOWLEDGEMENTS}

We would like to thank Siegfried Matthies for his expertise and an updated GeoMixSelf software. We appreciate the access to the SKAT neutron diffractometer at FLNP JINR, Dubna and to the Xray fluorescence analyzer at the Institute of Chemical Technology, Prague. We thank Dr Dilworth Parkinson for the opportunity to access the ALS Data Visualization Lab at LBNL, Berkeley. The authors express their gratitude to Anton Tremsin (UC Berkeley) and Jane Kanitpanyacharoen (Chulalongkorn University) for their help with the computed tomography analysis. This study was also supported by the Ministry of Education, project Kontakt II LH13102 and AMVIS, the program for U.S.-Czech Science and Technology Cooperation and by research projects 13-13967S, 16-03950S with funding provided by the Czech Science Foundation and by the Czech Academy of Sciences project RVO 67985831. HRW acknowledges grants from NSF (EAR-1343908) and DOE (DEFG02-05ER15637). This work has been partially supported by the French Agence Nationale de la Recherche through the 'Investissements d'avenir' program (ANR-10-EQPX-37 MATMECA grant). The authors would like to thank reviewers Luiz Morales and Douglas Schmitt for their comments that helped to improve the manuscript.

\section{REFERENCES}

Antao, S.M., Hassan, I., Wang, J., Lee, P.L. \& Toby, B.H., 2008. State-of-theart high-resolution powder X-ray diffraction (HRPXRD) illustrated with Rietveld structure refinement of quartz, sodalite, tremolite, and meionite, Can. Mineral., 46, 150-1509.

Backus, G.E., 1962. Long-wave elastic anisotropy produced by horizontal layering, J. geophys. Res., 67, 4427-4440.

Bambauer, H.-U., Eberhard, E. \& Visvanathan, K. 1967. The lattice constants and related parameters of 'plagioclase (low), Schweiz. Mineral. Petrog. Mitt. 47, 351-364.

Barruol, G., Mainprice, D., Kern, H., de Saint Blanquat, M. \& Compte, P., 1992. 3D seismic study of a ductile shear zone from laboratory and petrofabric data (Saint Barthélémy Massif, Northern Pyrenées, France), Terra Res., 4, 63-76.

Baudin, T., Marquer, D. \& Persoz, F., 1993. Basement-cover relationships in the Tambo nappe (Central Alps, Switzerland): geometry, structure and kinematics, J. Struct. Geol., 15, 543-553.

Berryman, J.G., 1980. Long-wavelength propagation in composite elastic media I. Spherical inclusions, J. acoust. Soc. Am., 68, 1809-1819.

Berryman, J.G., Grechka, V.Y. \& Berge, P.A., 1999. Analysis of Thomsen parameters for finely layered VTI medium, Geophys. Prospect., 47, 959978.

Birch, F., 1961. The velocity of compressional waves in rocks to 10 Kilobars, Part II, J. geophys. Res., 66, 2199-2224.

Brown, J.M., Abramson, E.H. \& Angel, R.J., 2006. Triclinic elastic constants for low albite, Phys. Chem. Miner., 33, 256-265.

Brown, J.M., Angel, R.J. \& Ross, N., 2016. Elasticity of plagioclase feldspars, J. geophys. Res., 121, 663-675.

Bunge, H.-J., 1982. Texture Analysis in Materials Science: Mathematical Methods, Butterworths.

Burlini, L. \& Fountain, D. M., 1993. Seismic anisotropy of metapelites from the Ivrea-Verbano zone and Serie dei Laghi (northern Italy), Phys. Earth planet. Inter, $\mathbf{7 8}, 301-317$.

Calderon, E., Gauthier, M., Decremps, F., Hamel, G., Syfosse, G. \& Polian, A., 2007. Complete determination of the elastic moduli of $\alpha$-quartz under hydrostatic pressure up to $1 \mathrm{GPa}$ : an ultrasonic study, J. Phys.-Condens. Mat., 19, 1-13, doi:10.1088/0953-8984/19/43/436228.
Catti, M., Ferraris, G., Hull, S. \& Pavese, A., 1994. Powder neutron diffraction study of 2M1 muscovite at room pressure and at $2 \mathrm{GPa}$, Eur. J. Miner., 6, 171-178.

Cholach, P.Y. \& Schmitt, D.R., 2006. Intrinsic elasticity of a textured transversely isotropic muscovite aggregate: comparisons to the seismic anisotropy of schists and shales, J. geophys. Res., 111, doi:10.1029/2005JB004158.

Cholach, P.Y., Molyneux, J.B. \& Schmitt, D.R., 2005. Flin Flon Belt seismic anisotropy: elastic heterogeneity, and shear-wave splitting, Can. J. Earth Sci., 42, 533-554.

Christensen, N.I., 1974. Compressional wave velocities in possible mantle rocks to pressures of 30 kilobars, J. geophys. Res., 79, 407-412.

Christensen, N.I. \& Szymanski, D.L., 1988. Origin of reflections from the Brevard fault zone, J. geophys. Res., 93, 1087-1002.

Costa e Silva, M.B. \& Stovas, A., 2009. Correspondence between the lowand high-frequency limits for anisotropic parameters in a layered medium, Geophysics, 74, WA25-WA33.

Dellinger, J. \& Vernik, L., 1994. Do traveltimes in pulse-transmission experiments yield anisotropic group or phase velocities?, Geophysics, 59, 1774-1779.

Downs, R.T., Hazen, R.M. \& Finger, L.W., 1994. The high-pressure crystal chemistry of low albite and the origin of the pressure dependency of Al-Si ordering, Am. Miner., 79, 1042-1052.

Gelinsky, S. \& Shapiro, S.A., 1997. Poroelastic Backus averaging for anisotropic layered fluid- and gas-saturated sediments, Geophysics, 62, $1867-1878$.

Grechka, V. \& Kachanov, M., 2006. Effective elasticity of fractured rocks: a snapshot of the work in progress, Geophysics, 71, W45-W58.

Gulson, B.L., 1973. Age relations in the Bergell region of the southeast Swiss Alps: with some geochemical comparisons, Eclogae Geol. Helv., 66, 293-313.

Hadley, K., 1976. Comparison of calculated and observed crack densities and seismic velocities in Westerly granite, J. geophys. Res., 81, 34843494.

Han, T., 2016. A simple way to model the pressure dependency of rock velocity, Tectonophysics, 675, 1-6.

Haerinck, T., Wenk, H.-R., Debacker, T.N. \& Sintubin, M., 2015. Preferred mineral orientation of a chloritoid-bearing slate in relation to its magnetic fabric, J. Struct. Geol., 71, 125-135.

Helbig, K., 1984. Anisotropy and dispersion in periodically layered media, Geophysics, 49, 364-373.

Heyliger, P., Ledbetter, H. \& Kim, S., 2003. Elastic constants of natural quartz, J. acoust. Soc. Am., 114, 644-650.

Hornby, B.E., 1998. Experimental laboratory determination of the dynamic elastic properties of wet, drained shales, J. geophys. Res., 103, $29945-$ 29964.

Hornby, B.E., Schwartz, L.M. \& Hudson, J.A., 1994. Anisotropic effectivemedium modeling of the elastic properties of shales, Geophysics, 59, $1570-1583$.

Hudson, J.A., 1980. Overall properties of a cracked solid, Math. Proc. Camb. Phil. Soc., 88, 371-384.

Ivankina, T.I., Kern, H.M. \& Nikitin, A.N., 2005. Directional dependence of $P$ - and $S$-wave propagation and polarization in foliated rocks from the Kola superdeep well: evidence from laboratory measurements and calculations, Tectonophysics, 407, 25-42.

Ivanov, Y. \& Stovas, A., 2016. Zero- and infinite-frequency limits of $P$-wave traveltime parameters in tilted orthorhombic media, in Proceedings of the 78th EAGE Expanded Abstracts, doi:10.3997/2214-4609.201600994.

Jäger, E., 1973. Die Alpine Orogenese im Lichte der radiometrischen Altersbestimmungen, Eclogae Geol. Helv., 66, 11-21.

Ji, S. \& Salisbury, M.H., 1993. Shear-wave velocities, anisotropy and splitting in high-grade mylonites, Tectonophysics, 221, 453-473.

Ji, S., Li, A., Wang, Q., Long, C., Wang, H., Marcotte, D. \& Salisbury, M., 2013. Seismic velocities, anisotropy, and shear-wave splitting of antigorite serpentinites and tectonic implications for subduction zones, J. geophys. Res., 118, 1015-1037.

Johnson, L. \& Wenk, H.-R., 1974. Anisotropy of physical constants in metamorphic rocks, Tectonophysics, 23, 79-98. 
Jung, H., 2011. Seismic anisotropy produced by serpentine in mantle wedge, Earth planet. Sci. Lett., 307, 535-543.

Kachanov, M., 1993. Elastic solids with many cracks and related problems, Adv. appl. Mech., 30, 259-445.

Kaercher, P., Militzer, B. \& Wenk, H.-R., 2014. Ab initio calculations of elastic constants of plagioclase feldspars, Am. Miner., 99, 2344-2352.

Kanitpanyacharoen, W., Wenk, H.-R., Kets, F., Lehr, B.C. \& Wirth, R., 2011. Texture and anisotropy analysis of Qusaiba shales, Geophys. Prospect., 59, 536-556.

Kanitpanyacharoen, W., Kets, F.B., Wenk, H.-R. \& Wirth, R., 2012. Preferred orientation, microstructures and porosity analyses of Posidonia shales, Clays Clay Miner., 60, 315-329.

Kanitpanyacharoen, W., Vasin, R., Wenk, H.-R. \& Dewhurst, D.N., 2015. Linking preferred orientations to elastic anisotropy in Muderong Shale, Australia, Geophysics, 80, C9-C19.

Keppler, R., Ullemeyer, K., Behrmann, J.H. \& Stipp, M., 2014. Potential of full pattern fit methods for the texture analysis of geological materials: implications from texture measurements at the recently upgraded neutron time-of-flight diffractometer SKAT, J. Appl. Crystallogr., 47, 1520-1534.

Kern, H. \& Wenk, H.R., 1990. Fabric-related velocity anisotropy and shear wave splitting in rocks from the Santa Rosa mylonite zone, California, J. geophys. Res., 95, 11 213-11 223.

Kern, H., Liu, B. \& Popp, T., 1997. Relationship between anisotropy of P and $\mathrm{S}$ wave velocities and anisotropy of attenuation in serpentinite and amphibolite, J. geophys. Res., 102, 3051-3065.

Kern, H., Popp, T., Gorbatsevich, F., Zharikov, A., Lobanov, K.V. \& Smirnov, Yu.P., 2001. Pressure and temperature dependence of $V_{P}$ and $V_{S}$ in rocks from the superdeep well and from the surface analogues at Kola and the nature of velocity anisotropy, Tectonophysics, 338, 113-134.

Kern, H., Mengel, K., Strauss, K.W., Ivankina, T.I., Nikitin, A.N. \& Kukkonen, I.T., 2009. Elastic wave velocities, chemistry and modal mineralogy of crustal rocks sampled by the Outokumpu scientific drill hole, Phys. Earth planet. Inter., 175, 151-166.

Kern, H., Lokajicek, T., Svitek, T. \& Wenk, H.-R., 2015. Seismic anisotropy of serpentinite from Val Malenco, Italy, J. geophys. Res., 120, 4113-4129.

Klíma, K., 1973. The computation of the elastic constants of an anisotropic medium from the velocities of body waves, Stud. Geophys. Geod., 17(2), $115-122$.

Lehmann, E.H., Vontobel, P. \& Wiezel, L., 2001. Properties of the radiography facility NEUTRA at SINQ and its potential for use as European reference facility, Nondestruct. Testing Evaluat., 16(2-6), 191-202.

Lippitsch, R., Kissling, E \& Ansorge, J., 2003. Upper mantle structure neneath the Alpine orogen from high-resolution teleseismic tomography, J. geophys. Res., 108, doi:10.1029/2002JB002016.

Little, T.A., Hacker, B.R., Brownlee, S.J. \& Seward, G., 2013. Microstructures and quartz lattice-preferred orientations in the eclogite-bearing migmatitic gneisses of the D'Entrecasteaux Islands, Papua New Guinea, Geochem. Geophys. Geosyst., 14, 2030-2062.

Liu, Y. \& Schmitt, D.R., 2006. The transition between the scale domains of ray and effective medium theory and anisotropy: numerical models, Pure appl. Geophys., 163, 1327-1349.

Lokajičcek, T. \& Svitek, T., 2015. Laboratory measurement of elastic anisotropy on spherical rock samples by longitudinal and transverse sounding under confining pressure, Ultrasonics, 56, 294-302.

Lokajíček, T., Kern, H., Svitek, T. \& Ivankina, T., 2014. 3D velocity distribution of $P$ - and $S$-waves in a biotite gneiss, measured in oil as the pressure medium: comparison with velocity measurements in a multi-anvil pressure apparatus and with texture-based calculated data, Phys. Earth planet. Inter., 231, 1-15.

Lutterotti, L., Matthies, S., Wenk, H.-R., Schultz, A.S. \& Richardson, J.W., 1997. Combined texture and structure analysis of deformed limestone from time-of-flight neutron diffraction spectra, J. appl. Phys., 81, 594600 .

Lutterotti, L., Chateigner, D., Ferrari, S. \& Ricote, J., 2004. Texture, residual stress and structural analysis of thin films using a combined X-ray analysis, Thin Solid Films, 450, 34-41.

Mah, M. \& Schmitt, D.R., 2001a. Near point-source longitudinal and transverse mode ultrasonic arrays for material characterization, IEEE Trans. Ultrason. Ferroelectr. Freq. Control., 48(3), 691-698.
Mah, M. \& Schmitt, D.R., 2001b. Experimental determination of the elastic coefficients of an orthorhombic material, Geophysics, 66(4), $1217-1225$.

Marion, D., Mukerji, T. \& Mavko, G., 1994. Scale effects on velocity dispersion - From ray to effective medium theories in stratified medium, Geophysics, 59, 1613-1619.

Matthies, S., 2002. 20 years WIMV, history, experience and contemporary developments, Mater. Sci. Forum, 408-412, 95-100.

Matthies, S., 2010. On the combination of self-consistent and geometric mean elements for the calculation of the elastic properties of textured multi-phase samples, Solid State Phenom., 160, 87-93.

Matthies, S., 2012. GEO-MIX-SELF calculations of the elastic properties of a textured graphite sample at different hydrostatic pressures, J. appl. Crystallogr., 45, 1-16.

Matthies, S. \& Humbert, M., 1995. On the principle of a geometric mean of even-rank symmetric tensors for textured polycrystals, J. appl. Crystallogr., 28, 254-266.

Matthies, S. \& Wenk, H.-R., 2009. Transformations for monoclinic crystal symmetry in texture analysis, J. appl. Crystallogr., 42, 564-571.

Meissner, R., Rabbel, W. \& Kern, H., 2006. Seismic lamination and anisotropy of the Lower Continental Crust, Tectonophysics, 416, 81-99.

Melendez-Martinez, J. \& Schmitt, D.R., 2016. A comparative study of the anisotropic dynamic and static elastic moduli of unconventional reservoir shales: implication for geomechanical investigations, Geophysics, 81(3), D245-D261.

Morris, P.R., 1970. Elastic constants of polycrystals, Int. J. Eng. Sci., 8, 49-61.

Mukerji, T., Mavko, G., Mujica, D. \& Lucet, N., 1995. Scaledependent seismic velocity in heterogeneous media, Geophysics, 60 , 1222-1233.

Nishizawa, O. \& Yoshino, T., 2001. Seismic velocity anisotropy in mica-rich rocks: an inclusion model, Geophys. J. Int., 145, 19-32.

O’Connell, R.J. \& Budiansky, B., 1974. Seismic velocities in dry and saturated cracked solids, J. geophys. Res., 79, 5412-5426.

Oertel, G., 1983. The relationship of strain and preferred orientation of phyllosilicate grains in rocks - review, Tectonophysics, 100, 413-447.

Ollion, J., Cochennec, J., Loll, F., Escudé, C. \& Boudier, T., 2013. TANGO: a generic tool for high-throughput $3 \mathrm{D}$ image analysis for studying nuclear organization, Bioinformatics, 29(14), 1840-1841.

Onel, Y., Lange, A., Staude, A., Ehrig, K., Kupsch, A., Hentschel, M.P., Wolk, T., Müller, B.R. \& Bruno, G., 2013. Evaluating porosity in cordierite diesel particulate filter materials, Part 2 statistical analysis of computed tomography data, J. Ceram. Sci. Technol., 5(01), 13-22.

Ong, O.N., Schmitt, D.R., Kofman, R.S. \& Haug, K., 2016. Static and dynamic pressure sensitivity anisotropy of a calcareous shale, Geophys. Prospect., 64, 875-897.

Pehl, J. \& Wenk, H.-R., 2005. Evidence for regional Dauphiné twinning in quartz from the Santa Rosa mylonite zone in Southern California. A neutron diffraction study, J. Struct. Geol., 27, 1741-1749.

Pros, Z. \& Babuška, V., 1968. An apparatus for investigating the elastic anisotropy on spherical rock samples, Stud. Geophys. Geod., 12, 192198.

Pros, Z., Lokajíček, T. \& Klíma, K., 1998. Laboratory approach to the study of elastic anisotropy on rock samples, Pure appl. Geophys., 151, 619-629.

Ruiz, F. \& Azizov, I., 2011. Tight shale elastic properties using the softporosity and single aspect ratio models, in Proceeding of the 81st Annual International Meeting, SEG, Expanded Abstracts, pp. 2241-2245.

Sander, B., 1950. Einführung in die Gefügekunde der Geologischen Körper. Zweiter Teil: Die Korngefüge, Springer-Verlag.

Sayers, C.M., 1994. The elastic anisotropy of shales, J. geophys. Res., 99, 767-774

Sayers, C.M. \& Kachanov, M., 1991. A simple technique for finding effective elastic constants of cracked solids for arbitrary crack orientation statistics, Int. J. Solids Struct., 27, 671-680.

Schijns, H., Schmitt, D.R., Heikkinen, P.J. \& Kukkonen, I.T., 2012. Seismic anisotropy in the crystalline upper crust: observations and modelling from the Outokumpu scientific borehole, Finland, Geophys. J. Int., 189, 541553. 
Schoenberg, M. \& Sayers, C.M., 1995. Seismic anisotropy of fractured rock, Geophysics, 60, 204-211.

Shapiro, S.A., 2003. Elastic piezosensitivity of porous and fractured rocks, Geophysics, 68, 482-486.

Siegesmund, S. \& Kern, H., 1990. Velocity anisotropy and shear-wave splitting in rocks from the mylonite belt along the Insubric Line (Ivrea Zone, Italy), Earth planet. Sci. Lett., 99, 29-47.

Siegesmund, S. \& Vollbrecht, A., 1991. Complete seismic properties obtained from microcrack fabrics and textures in an amphibolite from the Ivrea zone, Western Alps, Italy, Tectonophysics, 199, 13-24.

Siegesmund, S., Takeshita, T. \& Kern, H., 1989. Anisotropy of Vp and Vs in an amphibolite of the deeper crust and its relationship to the mineralogical, microstructural and textural characteristics of the rock, Tectonophysics, $157,25-38$.

Siegesmund, S., Vollbrecht, A. \& Nover, G., 1991. Anisotropy of compressional wave velocities, complex electrical resistivity and magnetic susceptibility of mylonites from the deeper crust and their relation to the rock fabric, Earth planet. Sci. Lett., 105, 247-259.

Svitek, T., Vavryčuk, V., Lokajíček, T. \& Petružálek, M., 2014. Determination of elastic anisotropy of rocks from $P$ - and $S$-wave velocities: numerical modelling and lab measurements, Geophys. J. Int., 199(3), $1682-1697$.

Toby, B.H., 2006. R factors in Rietveld analysis: how good is good enough?, Powder Diffr., 21, 67-70.

Tseng, H.-Y., Heaney, P.J. \& Onstott, T.C., 1995. Characterization of lattice strain induced by neutron irradiation, Phys. Chem. Miner, 22, 399-405.

Tullis, J. \& Wenk, H.-R., 1994. Effect of muscovite on the strength and lattice preferred orientations of experimentally deformed quartz aggregates, Mat. Sci. Eng., A175, 209-220.

Ullemeyer, K., Spalthoff, P., Heinitz, J., Isakov, N.N., Nikitin, A.N. \& Weber, K., 1998. The SKAT texture diffractometer at the pulsed reactor IBR-2 at Dubna: experimental layout and first measurements, Nucl. Instrum. Meth. A, 412, 80-88.

Ullemeyer, K., Siegesmund, S., Rasolofosaon, P.N.J. \& Behrmann, J.H., 2006. Experimental and texture-derived $P$-Wave anisotropy of principal rocks from the TRANSALP traverse: an aid for the interpretation of seismic field data, Tectonophysics, 414, 97-116.

Vasin, R.N., Wenk, H.-R., Kanitpanyacharoen, W., Matthies, S. \& Wirth, R., 2013. Elastic anisotropy modeling of Kimmeridge shale, J. geophys. Res., 118, 3931-3956.
Vasin, R.N., Lebensohn, R.A., Matthies, S., Tome, C.N. \& Wenk, H.-R., 2014. The influence of grain shape and volume fraction of sheet silicates on elastic properties of aggregates: biotite platelets in an isotropic matrix, Geophysics, 79, D433-D441.

Vaughan, M.T. \& Guggenheim, S., 1986. Elasticity of muscovite and its relationship to crystal structure, J. geophys. Res., 91, 4657-4664.

Waeselmann, N., Brown, J.M., Angel, R.J., Ross, N., Zhao, J. \& Kaminsky, W., 2016. The elastic tensor of monoclinic alkali feldspars, Am. Miner, 101, 1228-1231.

Walsh, J.B., 1965. The effect of cracks on the compressibility of rocks, $J$. geophys. Res., 70, 381-389.

Wang, Ch.-Y., Lin, W. \& Wenk, H.-R., 1975. The effect of water and pressure on velocities of elastic waves in a foliated rock, J. geophys. Res., 80, 10651069.

Wenk, H.-R., 1973. The structure of the Bergell Alps, Eclogae Geol. Helv, 66(2), 255-291.

Wenk, H.-R., Hsiao, J., Flowers, G., Weibel, M., Ayranci, B. \& Fejér, Z., 1977. A geochemical survey of granitic rocks in the Bergell Alps, Schweiz. Miner. Petrog. Mitt., 57, 233-265.

Wenk, H.-R., Matthies, S., Donovan, J. \& Chateigner, D., 1998. BEARTEX: a Windows-based program system for quantitative texture analysis, $J$. appl. Crystallogr., 31, 262-269.

Wenk, H.-R., Voltolini, M., Mazurek, M., Van, Loon L.R. \& Vinsot, A., 2008. Preferred orientations and anisotropy in shales: Callovo-Oxfordian shale (France) and Opalinus Clay (Switzerland), Clays Clay Miner., 56, 285-306.

Wenk, H.-R., Lutterotti, L. \& Vogel, S.C., 2010a. Rietveld texture analysis from TOF neutron diffraction data, Powder Diffr., 25, 283-296.

Wenk, H.-R., Kanitpanyacharoen, W. \& Voltolini, M., 2010b. Preferred orientations of phyllosilicates: comparison of fault gouge, shale and schist, J. Struct. Geol., 32, 478-481.

Wenk, H.-R., Vasin, R.N., Kern, H., Matthies, S., Vogel, S.C. \& Ivankina, T.I., 2012. Revisiting elastic anisotropy of biotite gneiss from the Outokumpu scientific drill hole based on new texture measurements and texture-based velocity calculations, Tectonophysics, 570-571, 123-134.

Yoneda, A. \& Sohag, F.H., 2011. Pore effect on macroscopic physical properties: composite elasticity determined using a two-dimensional buffer layer finite element method model, J. geophys. Res., 116, B03207, doi:10.1029/2010JB007500. 